\title{
Revisión taxonómica del género Eragrostis Wolf en Chile, basada en análisis estadísticos multivariados
}

\section{Taxonomic revision of Eragrostis Wolf from Chile, based on statistical multivariate analysis}

\author{
Inelia Escobar ${ }^{1}$, Eduardo Ruiz ${ }^{1}$, Víctor L. Finot ${ }^{2}$, María A. Negritto ${ }^{3}$ \& Carlos M. Baeza $^{1}$ \\ ${ }^{1}$ Departamento de Botánica, Facultad de Ciencias Naturales y Oceanográficas, Universidad de Concepción, Casilla 160-C, \\ Concepción, Chile. \\ ${ }^{2}$ Departamento de Producción Animal, Facultad de Agronomía, Universidad de Concepción, Casilla 537, Chillán, Chile. \\ ${ }^{3}$ Carrera 32 No 22 - 08, Apartado Postal 2-1-21630, Santa Marta D.T.C.H., Colombia. \\ iescobar@udec.cl
}

\begin{abstract}
RESUMEN
Eragrostis Wolf es un género cosmopolita que incluye alrededor de 350 especies, distribuidas principalmente en regiones tropicales y subtropicales. Debido al amplio rango de variación morfológica dentro del género, los límites específicos frecuentemente se sobreponen, siendo muy difícil establecer caracteres diagnósticos para delimitar las especies. Para Chile se han citado entre 10 y 15 taxones. El objetivo fue realizar una revisión de las especies del género Eragrostis que crecen en Chile, complementada con el uso de técnicas estadísticas multivariadas (análisis de conglomerados y análisis de coordenadas principales). Se determinó la presencia en Chile de 12 especies, 2 variedades y una subespecie. Ocho taxones son nativos y cuatro son introducidos. Se elaboró una clave, descripciones e ilustraciones de cada taxón, junto a su rango de distribución geográfica.
\end{abstract}

Palabras clave: Poaceae, análisis de coordenadas principales, análisis de conglomerados.

\begin{abstract}
Eragrostis Wolf is a cosmopolitan genus which includes nearly 350 species, mainly distributed in tropical and subtropical regions. Due to the wide range in variation within this genus, the species limits are often overlapping, making difficult to establish specific boundaries and diagnostic characters. Beetwen 10 and 15 species have been previously cited for Chile. The objective was to establish the limits and the diagnostic characters in Chilean taxa, using multivariate analysis (cluster analysis and principal coordinates analysis). Twelve species, two varieties and one subspecies are recognized in the present treatment. Eight taxa are native and 4 are introduced. A key, descriptions, illustrations and the geographical distribution of each species are given.
\end{abstract}

KEYWORDS: Poaceae, principal coordinates analysis, cluster analysis.

\section{INTRODUCCIÓN}

Eragrostis Wolf (Eragrostideae, Chloridoideae) reúne alrededor de 350 especies en el mundo; se distribuye en las regiones tropicales y subtropicales, preferentemente con climas áridos. Los centros de distribución del género son las sabanas del sur de África y el centro-norte de México (Clayton \& Renvoize 1986, Watson \& Dallwitz 1992, Peterson et al. 1995, 1997, Peterson \& Boechat 2001, Peterson 2003, Peterson \& Valdés-Reyna 2005).
Los representantes de la tribu Eragrostideae poseen una considerable variación morfológica. A nivel genérico e incluso tribal los límites morfológicos frecuentemente se sobreponen, por lo cual ha sido muy difícil señalar caracteres que delimiten los géneros. La mejor combinación de caracteres usada para diferenciar a Eragrostis de los otros géneros de la tribu son la presencia en Eragrostis de inflorescencias en panícula (ocasionalmente un racimo), 
espiguillas multifloras donde la desarticulación de la lemma y la pálea ocurren separadamente, lemmas usualmente 3nervias no aristadas, páleas arqueadas longitudinalmente con quillas escabrosas o ciliadas, a veces aladas y fotosíntesis C4, excepto en E. walteri Pilg. (Peterson et al.1995, 1997, Nicora 1998, Ingram \& Doyle 2004, Peterson \& ValdésReyna 2005).

En América crecen aproximadamente unas 111 especies (Peterson \& Valdés-Reyna 2005), en terrenos abiertos, suelos pobres o arenosos y en sitios cultivados. Algunas especies son forrajeras valiosas, especialmente en suelos áridos (Clayton \& Renvoize 1986, Nicora \& Rúgulo 1987, Watson \& Dallwitz 1992, Van den Borre \& Watson 1994) o constituyen malezas asociadas a cultivos (Matthei 1995). En Sudamérica se han realizado varios trabajos taxonómicos sobre Eragrostis, la mayoría de ellos regionales (Nicora 1973, 1994, 1998, Renvoize 1998, Tovar 1993, Boechat 1981, Boechat \& Longhi-Wagner 2000, 2001, Hitchcock 1927, Laegaard \& Peterson 2001, Peñaloza-Jiménez et al. 2002). Para Chile, Marticorena \& Quezada (1985), al igual que Nicora $(1994,1998)$, reconocen 10 especies (Tabla I), sin embargo ambos autores sólo coinciden en 6 de ellas $(E$. attenuata Hitchc., E. curvula (Schrad.) Nees, E. kuschelii Skottsb., E. nigricans (Kunth) Steud., E. peruviana (Jacq.) Trin. y E. polytricha Nees). Las especies E. elongata Jacq., E. mexicana (Hornem.) Link y E. vallensis (Schrad. ex Schult.) Schult. citadas por Marticorena \& Quezada (1985), no son reconocidas por Nicora (1998), quien a su vez cita para Chile a $E$ atrovirens (Desf.) Steud., E. pycnantha (Phil.) Nicora, E. tenuifolia (A.Rich.) Steud. y E. weberbaueri Pilg., señalando además a E. scabra Phil., como especie dudosa, y mencionando su afinidad con $E$. montufari (Kunth) Steud. Posteriormente, Peterson \& Boechat (2001), reconocen 13 especies, dos de las cuales poseen taxones infraespecíficos. Finalmente, Zuloaga et al. (2008) reconocen sólo 11 especies, 2 subespecies y 2 variedades, sin embargo, ambos autores no coinciden en algunos taxones, lo cual deja en evidencia la necesidad de una revisión taxonómica del género para Chile.

Debido al amplio rango de variación morfológica en Eragrostis, la distinción entre la mayoría de las especies es dificultosa (Peterson et al. 1997). Los límites específicos frecuentemente se sobreponen, por lo cual ha sido complicado señalar caracteres diagnósticos para las especies del género. La aplicación de técnicas numéricas multivariadas contribuye a reconocer grupos discretos de especímenes con mayor objetividad y los caracteres que permiten separarlos. Estas técnicas adquieren mucha importancia en grupos tan complicados como las gramíneas y han sido utilizados con buenos resultados en varios estudios taxonómicos (Phillips 1982, Giussani 2000, Giussani et al. 2000, Flores 2003, Sebola \& Balkwill 2009). Dentro de estas técnicas, el análisis de conglomerados y el de coordenadas principales, constituyen una buena herramienta para separar especies o grupos de especies similares morfológicamente (Randall \& Hilu 1986, Giussani et al. 2000, Henderson 2002, 2005, 2006, Cron et al. 2007), así como para generar nuevas variables que puedan expresar la información contenida en el conjunto original de datos (Pla 1986, Crisci \& López 1983). Sobre la base de los antecedentes antes señalados, el presente trabajo consistió en realizar la revisión taxonómica del género Eragrostis para Chile, aplicando métodos univariados y multivariados, con énfasis en análisis de conglomerados, coordenadas principales y análisis discriminante, con el fin de conocer la variación morfológica y determinar los caracteres diagnósticos que permitan delimitar y esclarecer el número de taxones que crecen en el país. Con los resultados de estos análisis, se elaboró una clave para la identificación de los taxones y sus descripciones, además de incorporar las ilustraciones de cada especie y su rango de distribución geográfica.

\section{MATERIALES Y MÉTODOS}

\section{Material DE ESTUdio}

Se revisaron 160 ejemplares provenientes de los herbarios CONC, ULS y SGO (abreviaciones de acuerdo a Holmgren et al. 1990), incluidos los materiales tipos de las especies nativas. El material tipo de las especies: E. atrovirens, E. curvula, E. pilosa, E. nigricans var. nigricans, E. tenuifolia, y E. polytricha no fue observado, basándose en este caso, en estudios taxonómicos previos (Nicora 1998, Peterson \& Boechat 2001, Cafferty et al. 2000). Debido a la gran cantidad de caracteres faltantes para muchos ejemplares, 83 especímenes fueron utilizados para los análisis estadísticos. El número de ejemplares por especie varió entre 2 y 10 , de acuerdo con la disponibilidad de material de herbario. En el material examinado se indican con un asterisco $\left(^{*}\right)$ los ejemplares incluidos en los análisis multivariados.

\section{CARACTERES}

Se definieron 63 variables morfológicas, correspondientes a 19 caracteres continuos y 44 discretos (Apéndice I). La mayoría de los caracteres fueron considerados en trabajos taxonómicos previos (Peterson et al. 1997, Peterson 2003, Nicora 1994, 1998). Caracteres de la vaina y la lámina fueron medidos sobre la penúltima hoja, y el ancho de ésta, sobre la región media de la lámina. Caracteres reproductivos fueron medidos sobre la caña floral más alta. Para los caracteres cualitativos se utilizó la moda y para los cuantitativos el promedio de las observaciones registradas en los especímenes de herbario. A continuación de las descripciones de cada especie, se destacan los caracteres diagnósticos derivados de los análisis. En el Apéndice II se indica el valor promedio $(\chi)$, desviación estándar $(\sigma)$, y el tamaño muestral (n) para cada variable cuantitativa. Los caracteres señalados para el género se ajustan a las especies que crecen en Chile. 
TABLA I. Tabla comparativa de los distintos taxones de Eragrostis reconocidos para Chile por diferentes autores.

TABLE I. Comparative table of Eragrostis taxons for Chile recognized by different autors.

\begin{tabular}{|c|c|c|c|c|}
\hline $\begin{array}{c}\text { Marticorena \& Quezada } \\
\text { (1985) }\end{array}$ & Nicora (1998) & $\begin{array}{l}\text { Peterson \& Boechat } \\
\text { (2001) }\end{array}$ & Zuloaga et al. (2008) & $\begin{array}{l}\text { Escobar et al. (este } \\
\text { trabajo) }\end{array}$ \\
\hline & $\begin{array}{l}\text { E. atrovirens (Desf.) } \\
\text { Steud. }\end{array}$ & & & $\begin{array}{l}\text { E. atrovirens (Desf.) } \\
\text { Steud. }\end{array}$ \\
\hline E. attenuata Hitchc. & E. attenuata Hitchc. & E. attenuata Hitchc. & E. attenuata Hitchc. & E. attenuata Hitchc. \\
\hline E. curvula (Schrad.) Nees & $\begin{array}{l}\text { E. curvula (Schrad.) } \\
\text { Nees }\end{array}$ & $\begin{array}{l}\text { E. curvula (Schrad.) } \\
\text { Nees }\end{array}$ & $\begin{array}{l}\text { E. curvula (Schrad.) } \\
\text { Nees }\end{array}$ & $\begin{array}{l}\text { E. curvula (Schrad.) } \\
\text { Nees }\end{array}$ \\
\hline E. elongata Jacq. & & $\begin{array}{l}\text { E. elongata (Wild.) J. } \\
\text { Jacq. }\end{array}$ & & \\
\hline \multirow[t]{2}{*}{$\begin{array}{l}\text { E. kuschelii Skottsb. ex } \\
\text { Kuschel }\end{array}$} & E. kuschelii Skottsb. & E. kuschelii Skottsb. & E. kuschelii Skottsb. & E. kuschelii Skottsb. \\
\hline & & E. lugens Nees & & \\
\hline \multirow[t]{2}{*}{$\begin{array}{l}\text { E. mexicana (Hornem.) } \\
\text { Link }\end{array}$} & & $\begin{array}{l}\text { E. mexicana (Hornem.) } \\
\text { Link subsp. mexicana }\end{array}$ & $\begin{array}{l}\text { E. mexicana (Hornem.) } \\
\text { Link subsp. mexicana }\end{array}$ & \\
\hline & & $\begin{array}{l}\text { E. mexicana subsp. } \\
\text { virescens (J. Presl. S.D. } \\
\text { Koch \& Sánchez Vega }\end{array}$ & $\begin{array}{l}\text { E. mexicana (Hornem.) } \\
\text { Link subsp. virescens } \\
\text { (J. Presl. S.D. Koch \& } \\
\text { Sánchez Vega }\end{array}$ & $\begin{array}{l}\text { E. mexicana (Hornem.) } \\
\text { Link subsp. virescens } \\
\text { (J. Presl. S.D. Koch \& } \\
\text { Sánchez Vega }\end{array}$ \\
\hline \multirow[t]{2}{*}{$\begin{array}{l}\text { E. nigricans (H.B.K.) } \\
\text { Steud. }\end{array}$} & $\begin{array}{l}\text { E. nigricans (Kunth) } \\
\text { Steud. }\end{array}$ & $\begin{array}{l}\text { E. nigricans (Kunth) } \\
\text { Steud. var. nigricans }\end{array}$ & $\begin{array}{l}\text { E. nigricans (Kunth) } \\
\text { Steud. var. nigricans }\end{array}$ & $\begin{array}{l}\text { E. nigricans (Kunth) } \\
\text { Steud. var. nigricans }\end{array}$ \\
\hline & $\begin{array}{l}\text { E. nigricans var. } \\
\text { punensis Nicora }\end{array}$ & $\begin{array}{l}\text { E. nigricans var. } \\
\text { punensis Nicora }\end{array}$ & $\begin{array}{l}\text { E. nigricans (Kunth) } \\
\text { Steud. var. punensis } \\
\text { Nicora }\end{array}$ & $\begin{array}{l}\text { E. nigricans (Kunth) } \\
\text { Steud. var. punensis } \\
\text { Nicora }\end{array}$ \\
\hline \multirow[t]{2}{*}{ E. peruviana (Jacq.) Trin. } & $\begin{array}{l}\text { E. peruviana (Jacq.) } \\
\text { Trin. }\end{array}$ & $\begin{array}{l}\text { E. peruviana (Jacq.) } \\
\text { Trin. }\end{array}$ & $\begin{array}{l}\text { E. peruviana (Jacq.) } \\
\text { Trin. }\end{array}$ & $\begin{array}{l}\text { E. peruviana (Jacq.) } \\
\text { Trin. }\end{array}$ \\
\hline & E. pilosa (L.) P. Beauv. & E. pilosa (L.) P. Beauv. & E. pilosa (L.) P. Beauv. & E. pilosa (L.) P. Beauv. \\
\hline \multirow[t]{3}{*}{ E. polytricha Nees } & E. polytricha Nees & E. polytricha Nees & E. polytricha Nees & E. polytricha Nees \\
\hline & $\begin{array}{l}\text { E. pycnantha (Phil.) } \\
\text { Nicora }\end{array}$ & $\begin{array}{l}\text { E. pycnantha (Phil.) } \\
\text { Parodi ex Nicora }\end{array}$ & $\begin{array}{l}\text { E. pycnantha (Phil.) } \\
\text { Parodi ex Nicora }\end{array}$ & $\begin{array}{l}\text { E. pycnantha (Phil.) } \\
\text { Parodi ex Nicora }\end{array}$ \\
\hline & $\begin{array}{l}\text { E. tenuifolia (A. Rich.) } \\
\text { Steud. }\end{array}$ & $\begin{array}{l}\text { E. tenuifolia (A. Rich.) } \\
\text { Hochst. ex Steud. }\end{array}$ & $\begin{array}{l}\text { E. tenuifolia (A. Rich.) } \\
\text { Hochst. ex Steud. }\end{array}$ & $\begin{array}{l}\text { E. tenuifolia (A. Rich.) } \\
\text { Hochst. ex Steud. }\end{array}$ \\
\hline \multicolumn{5}{|l|}{$\begin{array}{l}\text { E. vallensis (Schrad. ex } \\
\text { Schult.) Schult. }\end{array}$} \\
\hline \multirow[t]{2}{*}{ E. virescens J. Presl } & E. virescens Presl & & & \\
\hline & E. weberbaueri Pilg. & E. weberbaueri Pilg. & E. weberbaueri Pilg. & E. weberbaueri Pilg. \\
\hline
\end{tabular}


ANÁLISIS DE LOS DATOS

El análisis de los datos se llevó a cabo mediante la aplicación de métodos univariados y multivariados. Los métodos univariados, basados en análisis estadísticos descriptivos, muestran la distribución de los valores y la desviación estándar para cada una de las variables cuantitativas (caracteres) medidas para cada espécimen de cada especie, además de los valores aberrantes de cada variable. La variabilidad de los caracteres se representó en gráficos del tipo caja y bigote. Las diferencias morfológicas entre especies se determinaron mediante análisis de varianza (ANDEVA). Para la comparación de las medias se utilizó el test de rangos múltiples de Duncan. Las variables cuantitativas, con sus respectivas unidades de medida y abreviaciones utilizadas en los análisis se presentan en el Apéndice I. Los métodos multivariados aplicados fueron análisis de conglomerados (AC) y análisis de coordenadas principales (ACoP), recomendado para ser aplicado sobre matrices que contienen caracteres cuantitativos y cualitativos (Legendre \& Legendre 1983, Flores 2003, Henderson 2006, Cron et al. 2007, Sebola \& Balkwill 2009). Para discriminar los taxones se utilizó análisis discriminante (AD), basado en caracteres cuantitativos no correlacionados. Cada ejemplar fue considerado como una Unidad Taxonómica Operativa (OTU). La matriz básica de datos (MBD), de 83 OTUs (columnas) y 63 caracteres (filas), fue estandarizada por columna, sustrayendo de cada observación la media de la columna y dividiendo el resultado por la desviación estándar de los valores en la columna. La MBD está disponible por el autor y editor cuando sea requerida. Las variables que no mostraron distribución normal (lanter, lfruto, afruto y lglam) fueron normalizadas mediante transformación logarítmica. El análisis de conglomerados se llevó a cabo con el algoritmo de la media aritmética no ponderada (UPGMA, unweighted pair-group method using arithmetic averages), utilizando el coeficiente de distancia de Gower (Gower 1971). Se utilizó el coeficiente de correlación cofenético (r) para medir la distorsión entre la matriz de distancia original y el fenograma resultante (Sneath y Sokal 1973, Crisci \& López 1983, Sebola \& Balkwill 2009). El ACoP fue realizado utilizando el índice de distancia Gower y superponiendo un árbol de recorrido mínimo (ARM) a la proyección de las OTUs en el plano formado por las dos primeras coordenadas. Análisis discriminante (AD) fue realizado utilizando las 19 variables cuantitativas. Las relaciones de similitud obtenidas fueron consideradas en la elaboración de la clave dicotómica para la determinación de los taxones del género. Las especies que no fueron inicialmente separadas en el primer ACoP fueron analizadas sobre una segunda matriz básica de datos, la que se redujo a 43 OTUs y 45 caracteres. Los análisis de los datos fueron llevados a cabo con los programas NTSyS-pc, versión 2.20L (Rohlf 2005) e InfoStat 2009 (Di Rienzo et al. 2009).

\section{RESULTADOS}

Los resultados de los análisis de conglomerados y coordenadas principales muestran 13 grupos de OTUs que se corresponden con entidades taxonómicas reconocidas en el presente tratamiento. La variación de los caracteres morfológicos cuantitativos es reflejada en la Figura 1. El fenograma (Fig. 2) obtenido a partir del análisis de conglomerados (índice de correlación cofenético $=0,96$ ), indica una buena representación de la matriz de distancia (Sneath \& Sokal 1973, Crisci \& López 1983) y muestra dos grandes conglomerados (I y II), que reflejan sólo un patrón de distribución geográfica, no coincidiendo con propuestas infragenéricas previas (Clayton \& Renvoize 1986, Van den Borre \& Watson 1994). Ambos conglomerados se separan a un nivel de distancia de 0,55 . El conglomerado I reúne las especies E. attenuata, E. kuschelii, E. peruviana, E. pycnantha y E. weberbaueri, con distribución en el norte de Chile y sur de Perú. El conglomerado II reúne las especies E. atrovirens, E. mexicana subsp. virescens, E. pilosa, E. nigricans var. nigricans, E. nigricans var. punensis, E. tenuifolia, E. polytricha y E. curvula, las cuales poseen distribución cosmopolita o amplia en Sudamérica, a excepción de E. nigricans, la cual crece en el altiplano de Chile y Argentina.

El ACoP fue llevado a cabo usando las mismas variables y OTUs usados en el AC. El primer ACoP muestra ocho grupos de OTUs (Fig. 3), correspondientes a E. attenuata, E. kuschelii, E. peruviana, E. pycnantha, E. weberbaueri, E. polytricha, E. tenuifolia y E. nigricans var. punensis. Las dos primeras coordenadas explican el 48,6\% de la varianza. Los cinco grupos que se disponen sobre el extremo positivo de la coordenada 1 corresponden a las especies que contiene el conglomerado I del AC. E. polytricha es separado del resto de los grupos hacia el extremo positivo de la coordenada 2 y negativo de la coordenada 1. En el extremo negativo de ambas coordenadas se agrupa el resto de los taxones, mostrando un considerable grado de solapamiento, los cuales fueron analizados con un segundo ACoP (Fig. 4), y que corresponden en su mayoría a los taxones agrupados en el conglomerado II del AC (Fig. 2).

Todas las entidades taxonómicas conforman conglomerados claros y diferenciables en el AC, a excepción de la OTU e9 (Fig. 2) correspondiente a un ejemplar de E. mexicana subsp. virescens, lo cual es también evidenciado por los resultados del segundo ACoP (Fig. 4). La tabla de clasificación cruzada obtenida en el análisis discriminante (AD) muestra un error promedio de $3,61 \%$, esto es, que un $96,4 \%$ de las OTUs se encuentra correctamente clasificado en los 10 grupos considerados.

Los taxones que forman el conglomerado I (E. attenuata, E. kuschelii, E. peruviana, E. pycnantha y E. weberbaueri) se caracterizan por presentar vainas y láminas pilosas, inflorescencias contraídas, densamente espiculadas con 

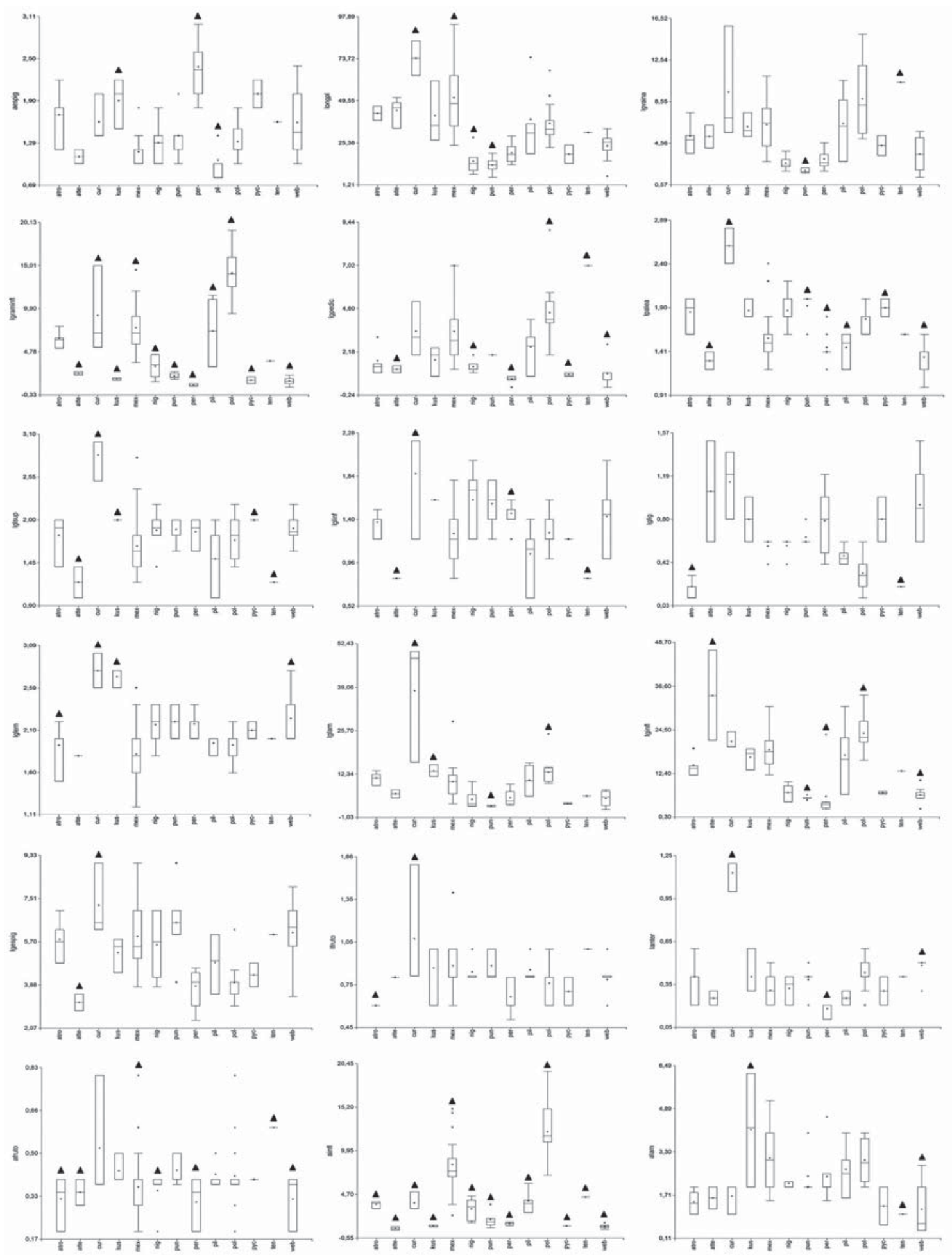

FIgURA 1. Gráficos de caja y bigote que muestra el rango completo de variación para los 18 caracteres cuantitativos. Cajas indican valores medios y los puntos fuera de ellos los valores extremos o aberrantes. Datos graficados corresponden a valores no transformados. Triángulos sobre las cajas indican diferencias significativas $(\mathrm{p} \leq 0,05)$.

FIGURE 1. Box-and-whisker plots showing the entire range of variation of 18 quantitative characters. Boxes incorpore median values. Points indicate outside values (aberrant). Graphics data correspond to non-transformed value. Triangle on box indicate significative differences $(\mathrm{p} \leq 0,05)$. 


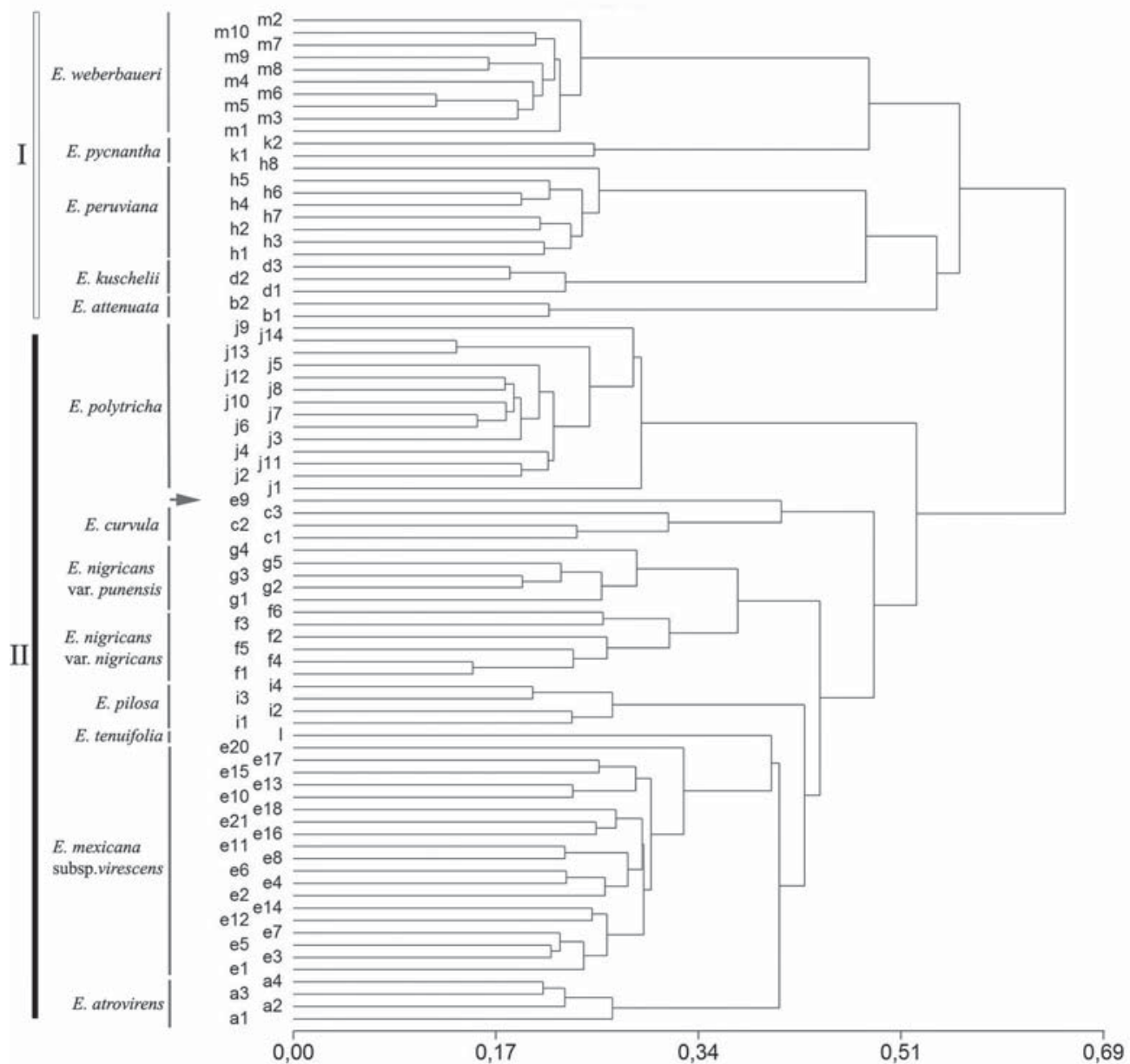

Figura 2. Fenograma resultante del análisis de conglomerados, basado en el estudio de 83 ejemplares de Eragrostis, mostrando los dos principales conglomerados. Índice de correlación cofenético 0,96.

FIGURE 2. Phenogram resulting from UPGMA cluster analysis based on 83 specimens of Eragrostis, showing two principal cluster. Cophenetic correlation 0,96 .

espiguillas hasta la base de la ramas, pulvínulos ausentes, espiguillas oblongas (excepto E. pycnantha), raquillas frágiles (excepto E. kuschelii), superficie dorsal de la pálea escabrosa (excepto E. peruviana) y las cariopsis sin surco ventral. Dentro de este conglomerado, la primera separación la constituye el taxón E. attenuata, a un nivel de distancia de 0,55 , seguido por los subconglomerados formados por los taxones E. kuschelii + E. peruviana y E. pycnantha $+E$. weberbaueri (distancia $=0,47$ ), los cuales fueron delimitados por los caracteres: indumentos de los nudos, indumentos de los entrenudos, pilosidad del eje de la inflorescencia, textura del eje de la inflorescencia, tipo de láminas, tipo de ápice de las láminas, consistencia de las glumas, forma de las lemmas, superficie dorsal de las lemmas, tipo de ápice de las páleas y largo de la mácula embrional sobre el fruto. Las variables discriminantes cuantitativas que separan estos cinco taxones son: ancho de la espiguilla (E. peruviana), largo de la lemma (E. weberbaueri), ancho de la lámina ( $E$. kuschelii), largo de la gluma superior (E. pycnantha) y largo de la inflorescencia (E. attenuata).

Los taxones pertenecientes al conglomerado II (E. atrovirens, E. mexicana subsp. virescens, E. pilosa, E. nigricans var. nigricans, E. nigricans var. punensis, E. tenuifolia, E. polytricha y E. curvula) se caracterizan por poseer inflorescencias amplias, laxas, ejes glabros con presencia de pulvínulos, espiguillas distribuidas en el ápice de las ramas, páleas glabras, vainas y láminas generalmente glabras. Dentro de este conglomerado el primer nivel de separación o subconglomerado lo evidencia E. polytricha (distancia=0,5), lo cual se muestra en los resultados del primer ACoP (Fig. 3), donde los OTUs de este taxón se agrupan claramente en el extremo positivo de la coordenada 2 y negativo de la coordenada 1 . Los caracteres que definen esta especie son: forma de la espiguilla, coloración de las espiguillas, número de antecios, forma de las lemmas, consistencia de las páleas, persistencia de las páleas, 
forma del fruto y las variables cuantitativas: largo de las ramas de la inflorescencia, largo de la lámina y ancho de la inflorescencia.

Los especímenes correspondientes a E. atrovirens, E.nigricans var. nigricans y E. nigricans var. punensis se agrupan en el AD, pero constituyen grupos independientes o subconglomerados en el ACoP y AC. La combinación de caracteres que definen a E. nigricans son, glándulas sobre los nervios de las hojas e inflorescencias, espiguillas violáceas, ápice de las lemmas obtusos y la macula embrional menor a la mitad de la longitud del fruto. Los caracteres que discriminan entre las dos variedades $E$. nigricans var. nigricans y E. nigricans var. punensis, son altura de la planta, largo de las ramas de la inflorescencia, número de antecios, tipo de inflorescencia y persistencia de la pálea. Los caracteres ancho de la lámina, largo y forma de la espiguilla permiten discriminar a E. atrovirens del resto de los especímenes de E. nigricans.

Los taxones E. curvula, E. pilosa y E. tenuifolia, constituyen grupos bien delimitados por el AC y segundo ACoP, sin embargo los caracteres cuantitativos no permiten discriminar a estos taxones de E. mexicana subsp. virescens (Fig. 5). Los caracteres cualitativos que permiten separar a estos cuatro taxones son principalmente: tipo de lámina, forma de la espiguilla, número de antecios, tipo de lígula, glándulas sobre eje de la inflorescencia, persistencia de la pálea y presencia o ausencia de surco ventral sobre el fruto. Sin embargo, los caracteres que caracterizan a E. curvula del resto de los taxones son principalmente cuantitativos, tales como: altura de la planta, largo de la lámina, ancho de la inflorescencia, largo de la espiguilla, largo de las glumas, lemmas y páleas, y largo del fruto.

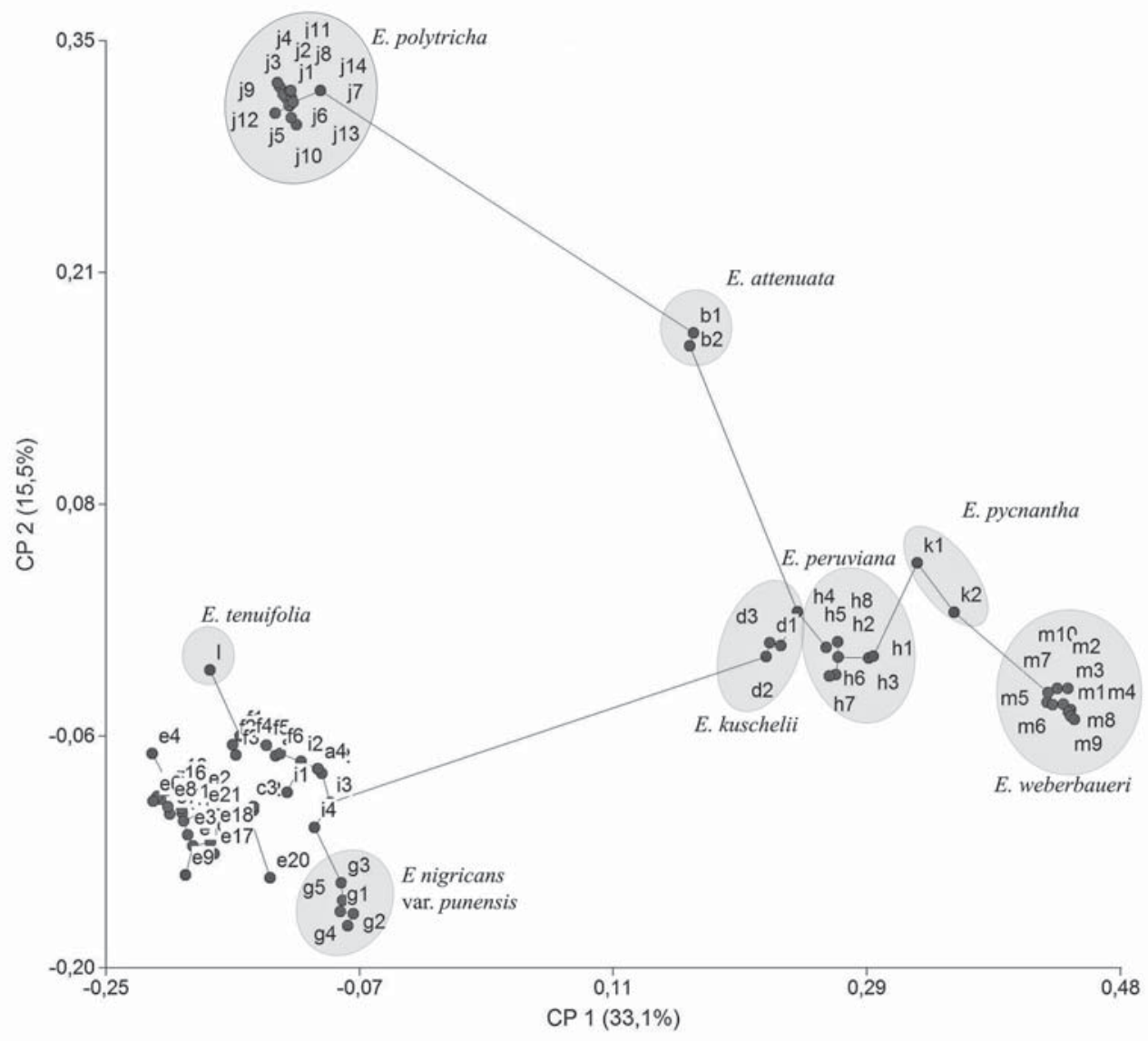

FigURA 3. Proyección de las 83 OTUs en el espacio conformado por las coordenadas 1 y 2 , correspondientes al primer análisis de coordenadas principales, las cuales reúnen el 33,1\% y $15,5 \%$ de la variación total, respectivamente. Se reconocen 8 grupos correspondientes a entidades taxonómicas reconocidas por el tratamiento taxonómico. E. attenuata, E. kuschelii, E. peruviana, E. pycnantha, E. weberbaueri, E. polytricha, E. tenuifolia y E. nigricans var. punensis.

Figure 3. Plot of 83 OTUs on the coordenates 1 and 2, corresponding to first PCoA. The first and second coordenates explain 33,1\% and $15,5 \%$ of the total variation, respectively. Eight groups corresponding to taxonomic units are recognized. E. attenuata, E. kuschelii, E. peruviana, E. pycnantha, E. weberbaueri, E. polytricha, E. tenuifolia and E. nigricans var. punensis. 


\section{DISCUSIÓN}

En el presente tratamiento se reconocen 13 taxones de los cuales 12 son especies y 3 son entidades taxonómicas infraespecíficas (1 subespecie y 2 variedades). Los taxones son claramente distinguibles entre sí, sobre la base de combinaciones de caracteres cuantitativos y cualitativos, obtenidos a partir de metodología multivariada. El estudio de los caracteres para los taxones de Eragrostis que crecen en Chile establece que la delimitación de taxones es más compleja para las especies que presentan una amplia distribución, que para aquéllas nativas del norte de Chile.

El análisis de conglomerados muestra 13 grupos correspondientes a 13 taxones, bien delimitados y claramente reconocibles, a excepción de un ejemplar de E. mexicana subsp. virescens (e9, Fig. 2), el cual se separa del resto de los ejemplares de esta especie y presenta mayor similitud a ejemplares de E. curvula. Esta separación es también soportada por los resultados del segundo ACoP (Fig. 4). La explicación a dicha separación estaría dada principalmente por caracteres cuantitativos (altura de la planta, ancho de la inflorescencia), debido a las amplias dimensiones alcanzadas por este ejemplar (outlier), el que sin duda corresponde a uno de E. mexicana subsp. virescens. Esta última subespecie muestra un amplio rango de variación morfológica en comparación al resto de los taxones que crecen en Chile, lo cual respondería probablemente a su amplio rango de distribución en el país y adaptación a particulares condiciones ambientales.

Los caracteres: tipo de inflorescencia, indumentos de las cañas, vainas, láminas y eje de la inflorescencia, distribución de las espiguillas en la panícula, presencia o ausencia de pulvínulos y forma de las espiguillas son importantes en la separación y distinción entre los dos mayores conglomerados. El conglomerado I del fenograma reúne a especies nativas con distribución entre el sur de Perú y el norte de Chile. Todas ellas se caracterizan por ser plantas muy pilosas, con panículas contraídas, espiciformes y densamente espiculadas, caracteres reportados para algunas especies presentes en este tipo de ambiente (Fahn \& Cutler 1992, Cutler et al. 2008).

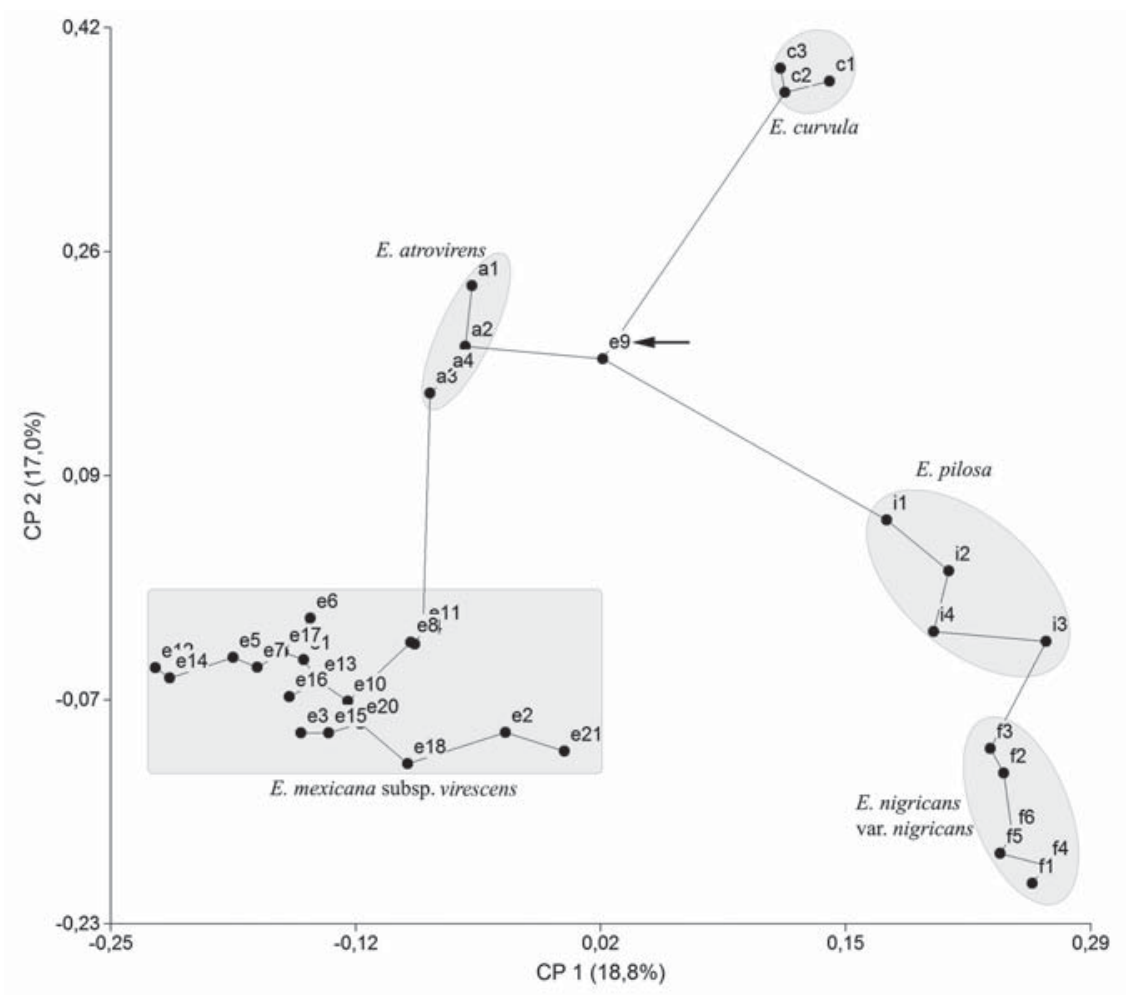

FigURA 4. Proyección de las 43 OTUs en el espacio conformado por las coordenadas 1 y 2 correspondientes al segundo análisis de coordenadas principales, las cuales reúnen el 18,8\% y $17 \%$ de la variación total, respectivamente. Se reconocen cinco grupos correspondientes a entidades taxonómicas reconocidas por el tratamiento taxonómico. E. atrovirens, E. pilosa, E. curvula, mexicana subsp. virescens y E. nigricans var. nigricans.

Figure 4. Plot of 43 OTUs on the two first components corresponding to second PCoA. The first and second PCO axes explain $18,8 \%$ and $17,0 \%$ of the total variation, respectively. Five groups corresponding to taxonomic units are recognized. E. atrovirens, E. pilosa, E. curvula, mexicana subsp. virescens y E. nigricans var. nigricans. 


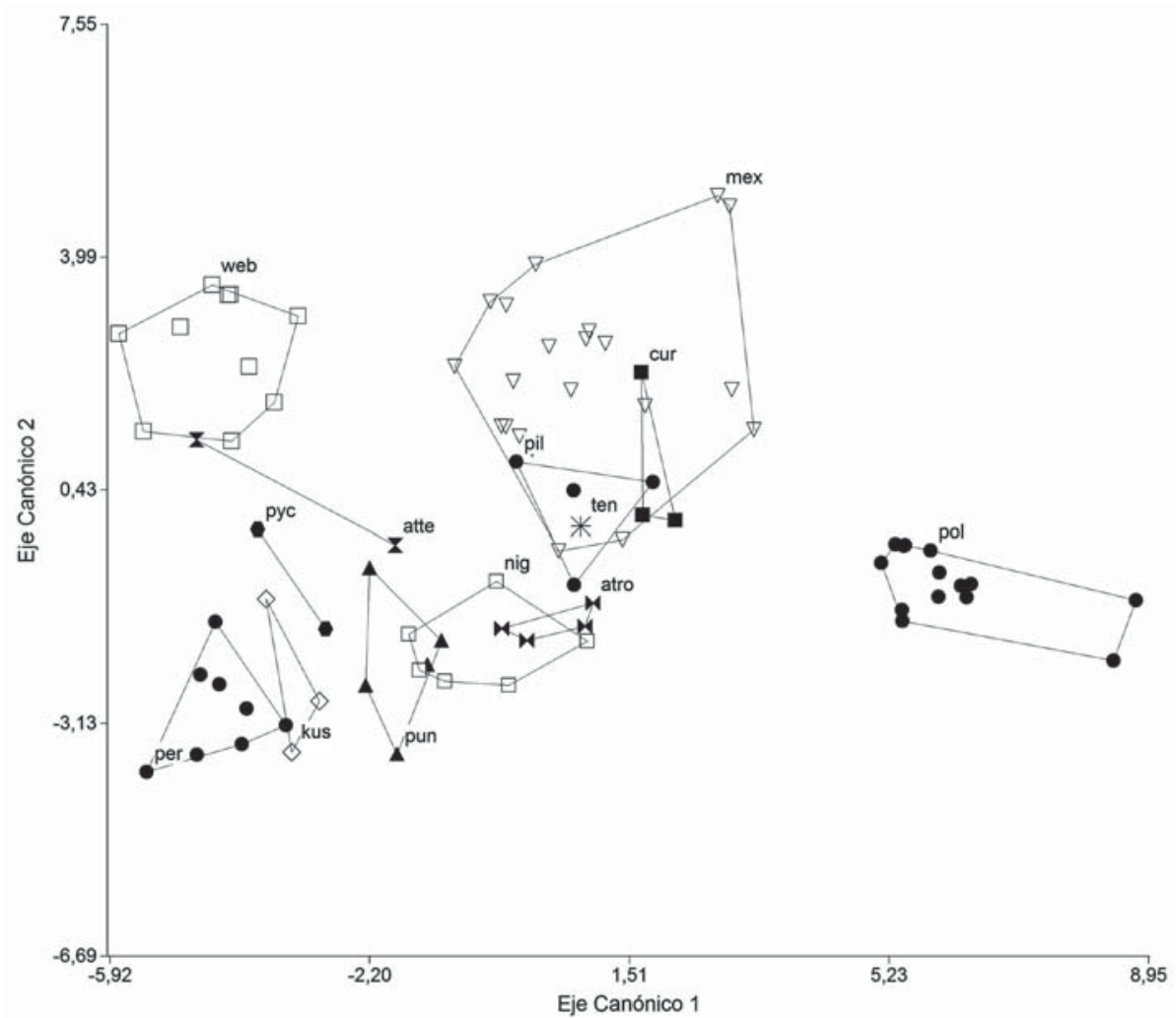

FIgURA 5. Proyección del resultado del Análisis Discriminante para las 83 OTUs y 19 caracteres morfológicos estudiados.

FigURE 5. Plot of the Discriminant analysis of 19 quantitative morphological data for 83 studied specimens.

El conglomerado II reúne especies nativas y adventicias que se distribuyen principalmente en la región centro-sur del país, y se caracterizan por la presencia de panículas amplias, glabras y con espiguillas apicales.

Diferente número de especies y nombres han sido reconocidos por distintos autores en trabajos previos (Marticorena \& Quezada 1985, Nicora 1998, Peterson \& Boechat 2001 y Zuloaga et al. 2008). En el presente estudio no se describen especies nuevas ni se dan nuevos nombres para el género en Chile, sin embargo, se clarifica la taxonomía del grupo para el país. Como se puede apreciar en la Tabla I, sólo siete taxones son reconocidos por todos los autores, incluido el presente trabajo, aún así, existen discrepancias que es pertinente aclarar. Peterson \& Boechat (2001) y Zuloaga et al. (2008) citan la subespecie E. mexicana subsp. mexicana para Chile, sin embargo el material de referencia (Peterson 15685, CONC) señalado por este último autor corresponde a un ejemplar de $E$. nigricans var. nigricans, por lo cual E. mexicana estaría representada en Chile, sólo por la subespecie E. mexicana subsp. virescens. Con relación a E. elongata que ha sido citada para Chile (Marticorena \& Quezada 1985, Peterson \& Boechat 2001), los ejemplares de herbario señalados corresponden a especímenes de E. atrovirens (Fuentes s.n.;
Sudzuki 651, SGO). Lo mismo ocurre con los ejemplares de E. leptostachya (R.Brown) Steud. y E. spartinoides Steud., citados para Isla de Pascua (Zizka 1991). En el presente tratamiento se reconoce a $E$. atrovirens al igual que Nicora (1998). Sin embargo, debido a la falta de antecedentes no se reconoce la presencia de E. lugens para Chile, la cual crece en países vecinos, concordando con Nicora (1998) y Zuloaga et al. (2008). Finalmente, E. vallensis citado para Chile (Marticorena \& Quezada 1985) corresponde a un error tipográfico, debiendo decir E. bahiensis Schrad. ex Schult., la cual crece en países vecinos (Marticorena. com. pers.).

Tratamiento taxonómico de las especies de ERAGROStIS PARA CHILE

Eragrostis Wolf, Gen. P1.: 23. 1776.

Etimol.: del griego Eros $=$ dios del amor y agrostis $=$ una gramínea.

Plantas anuales o perennes, desde 5,6-93,5 cm de altura, cespitosas. Cañas simples, erectas o decumbentes, glabras o pilosas. Vainas generalmente cerradas, de 1,3-15,8 cm de altura, glabras o pilosas, con pelos simples o tuberculados, a veces con largos mechones de pelos a ambos costados de 
la lígula. Lígulas ciliadas o pilosas, de 0,1-1,5 cm. Láminas lineares, planas, convolutas o involutas, de 1,4-50 cm x 0,4$6,2 \mathrm{~mm}$, con ápice generalmente agudo.

Panículas laxas, amplias o contraídas, de 2,5-46,5 cm x 0,4-19,5 cm, con ramificaciones laterales tenues, o panículas espiciformes, densas, con ramificaciones cortas arrimadas al eje, frecuentemente densamente espiculadas, terminales o axilares e incluidas en las vainas y con flores cleistógamas, de 0,6-19,2 cm. Espiguillas (1)-2-multifloras, comprimidas lateralmente, de 2,4-9 $\mathrm{mm}$ x 0,8-3 $\mathrm{mm}$, pediceladas, raro subsésiles, raquilla frágil o persistente, desarticulándose por debajo o por arriba de las glumas o entre los antecios. Pedicelos de 0,2-9 mm. Raquilla prolongada y terminada en una flor fértil. Glumas 2, 1-nervia, de 0,6-3 mm, agudas o acuminadas, persistentes o caducas. Lemmas carinadas, de 1,2-3 mm x 0,5-2,4 mm, agudas, múticas, raro mucronuladas, glabras o escabrosas, raro pilosas, 3(4-5)-nervias. Nervios laterales conspicuos o inconspicuos. Desarticulación de la lemma y la pálea ocurren separadamente. Páleas bicarinadas, de 1-2,8 mm, carinas escabrosas, ciliadas o escabrosas. Lodículas 2. Estambres 3, anteras de 0,1-1,2 mm. Ovario glabro, con 2 estilos y estigmas plumosos. Base del estilo persistente sobre el fruto joven. Cariopsis reticulada o lisa, a veces translúcida, de 0,2-0,8 $\mathrm{mm}$ x 0,5-1,6 mm, con o sin surco ventral, mácula embrional $1 / 2$ ó $1 / 3$ de la longitud del fruto, hilo punctiforme.

\section{Especie tipo: Eragrostis minor Host}

\section{DiSTRIBUCIÓN GEOGRÁFICA}

El género se encuentra ampliamente distribuido en Chile, encontrándose desde la Región de Arica-Parinacota hasta la Región de Magallanes, aunque no ha sido hasta ahora recolectado en la Región de Aisén. Los taxones con panículas contraídas o espiciformes (grupo I del fenograma) se distribuyen en la zona norte del país, entre la Región de AricaParinacota y la Región de Atacama. Eragrostis pycnantha y E. kuschelii, son endémicas de la Región de Atacama. E. pycnantha crece en territorio continental y E. kuschelii en las Islas Desventuradas. Eragrostis. peruviana es citada sólo para Chile (Zuloaga et al. 2008), sin embargo, junto a E.attenuata, y E. weberbaueri, corresponden a especies nativas del norte de Chile y centro-sur de Perú, creciendo generalmente en campos abiertos, con suelos arenosoarcillosos (Nicora 1998, Tovar 1993). Eragrostis peruviana crece en territorio insular, en las Islas Desventuradas y al igual que E. kuschelii es común en zonas altas, sobre todo en el fondo de las quebradas, sin embargo, es escasa en los faldeos, no así E. kuschelii, la cual habita en toda la isla, pero no es muy abundante (Skottsberg 1963). Por otro lado, dentro del grupo de panículas laxas las especies E. atrovirens, E. tenuifolia y E. curvula, originarias de Eurasia y África, poseen distribución tropical y subtropical, mientras E. pilosa crece casi en todo el mundo en las regiones tropicales y templadas. Eragrostis atrovirens y $E$. tenuifolia se han encontrado creciendo en la Isla de Pascua y E. curvula y E. pilosa constituyen especies forrajeras en países vecinos (Nicora 1998), no así en Chile, las cuales son poco abundantes y se distribuyen en las provincias centrales. Eragrostis nigricans, de distribución altoandina y puneña, crece en las regiones de Arica-Parinacota y Antofagasta, hasta los $3.000 \mathrm{~m}$ de altitud. Eragrostis mexicana subsp. virescens, nativa de Sudamérica, posee el rango más amplio de distribución en Chile, encontrándose sin discontinuidad desde la Región de Arica-Parinacota hasta la Región de Los Ríos, generalmente asociada a cultivos; similar situación presenta E. polytricha, también de distribución sudamericana y presente en la zona centrosur del país.

Clave para el reconocimiento de las especies de Eragrostis Que crecen en Chile

1. Inflorescencias espiciformes, contraídas, con ejes generalmente pilosos, pulvínulos ausentes, espiguillas llegan a la base de las ramas, espiguillas oblongas rara vez lanceoladas, raquillas generalmente frágiles, páleas generalmente escabrosas. Vainas y láminas pilosas.

2. Nudos pilosos, presencia de glándulas en las cañas, ejes de las panículas escabrosos, láminas convolutas, obtusas, páleas agudas...

3. Entrenudos glabros. Espiguillas con 11 a 15 antecios, glumas obtusas con los márgenes glabros, ápices denticulados, superficie dorsal de las lemmas escabrosas, nervaduras de las páleas escabrosas, longitud macula embrional igual a la mitad de la longitud del fruto

E. weberbaueri

3'. Entrenudos pilosos. Espiguillas con 3 a 7 antecios, glumas agudas con los márgenes escabrosos y ciliados, ápices enteros, superficie dorsal de las lemma escabrosas y ciliadas, nervaduras de las páleas escabrosas y ciliadas, longitud de la mácula embrional menor a la mitad de la longitud del fruto.

E. pycnantha

2'. Nudos glabros, cañas eglandulosas, ejes de las panículas no escabrosos, láminas planas, agudas o acuminadas, páleas obtusas. ..4 
4. Inflorescencias lineares, de 21,6-46,5 cm de longitud, con ejes glabros, espiguillas violáceas, glumas membranáceas con márgenes escabrosos, lemmas oval-lanceoladas.

4'. Inflorescencias oblongas, de 1,9-23,2 cm de longitud, con ejes pilosos, espiguillas oliváceas, glumas herbáceas con márgenes glabros o ciliados, lemmas lanceoladas.

5. Láminas agudas, lígulas pestañosas. Inflorescencias de 13-20 cm de longitud, páleas caedizas, nervadura de las páleas escabrosa y ciliada.

5'. Láminas acuminadas, lígulas pilosas. Inflorescencias 2,5-7 (23) $\mathrm{cm}$ de longitud, páleas persistentes, nervadura de las páleas ciliada.

1'. Inflorescencias no espiciformes, generalmente laxas, con ejes glabros, pulvínulos presentes, espiguillas generalmente no llegan a la base de las ramas, espiguillas lineares a lanceolado-oblongas, rara vez lanceoladas, raquillas generalmente persistentes, páleas glabras. Vainas y láminas generalmente glabras................................................. 6. Plantas perennes, con vainas menores o mayores que los entrenudos y pocos ejes floríferos, poco

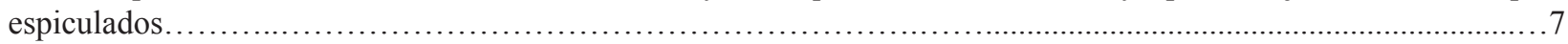

7. Vainas mayores que los entrenudos, glumas lanceoladas a oval lanceoladas, lemmas ovadas u oblongas, lemmas y páleas de similar longitud.

8. Espiguillas lanceoladas, violáceas, con 3-7 antecios, lemmas ovadas, páleas membranáceas, caedizas, fruto de forma cuadrangular. Hojas con pelos de base tuberculada. ................................... polytricha

8'.Espiguillas lineares, oliváceas, con 5-10 antecios, lemmas oblongas, páleas herbáceas, persistentes, frutos ovados. Hojas glabras........................................................................................... tenuifolia

7'. Vainas menores que los entrenudos, glumas linear-lanceoladas, lemmas oval-lanceoladas, páleas $3 / 4$ de la longitud de la lemmas.

9.Laminas planas, de 4,9-13,4 cm. Inflorescencias eglandulosas, espiguillas lanceolado-oblongas, con 1115 antecios, márgenes de las glumas glabros, lemmas glabras, páleas membranáceas............ atrovirens 9'. Laminas filiformes, de $16-48 \mathrm{~cm}$. Inflorescencias glandulosas, espiguillas linear-lanceoladas, con 37 antecios, márgenes de las glumas escabrosos, lemmas escabrosas, páleas herbáceas...E. curvula

6'. Plantas anuales, con vainas menores que los entrenudos y múltiples ejes floríferos densamente espiculados............10

10. Panículas de hasta $31 \mathrm{~cm}$ de largo, con ramas basales de hasta 14,5 $\mathrm{cm}$ de largo. Espiguillas oliváceas, ápices de las lemmas agudos. Cariopsis con mácula embrional igual a la mitad de la longitud del fruto.

11. Cañas eglandulosas. Pulvínulos pilosos. Glumas obtusas, lemmas escabrosas con nervios conspicuos, páleas caedizas, páleas $3 / 4$ de la longitud de las lemmas. Cariopsis sin surco ventral.

... pilosa

11'. Cañas glandulosas. Pulvínulos glabros. Glumas agudas, lemmas generalmente glabras con nervios inconspicuos, páleas persistentes y de similar longitud a las lemmas. Cariopsis con surco ventral.

E. mexicana subsp. virescens

10'. Panículas de hasta $10 \mathrm{~cm}$ de largo, con ramas basales de hasta $4,5 \mathrm{~cm}$ de largo. Espiguillas violáceas, ápice de las lemmas obtuso. Cariopsis con mácula embrional menor a la mitad de la longitud del fruto

.E. nigricans

\section{DESCRIPCIÓN DE LAS ESPECIES}

1. Eragrostis atrovirens (Desf.) Trin. ex Steud., Nomencl. Bot., (ed. 2) 1: 562. 1840. Poa atrovirens Desf., Fl. Atlant. 1: 73. 1798. TIPO: Algeria. "Habitat in arvis incultis prope La Calle", Desfontaines 160 [holotipo: FI; isotipo: BAA, LE, P].

Iconografía: Fig. 6.

Plantas perennes, cespitosas, de 22,6-51,5 cm. Cañas erectas, a veces geniculadas, 1-4-nodes, no ramificadas, nudos y entrenudos glabros. Vainas glabras, menores que los entrenudos, de 3,0-8,6 cm. Lígulas ciliadas, de 0,1-0,3 $\mathrm{mm}$. Láminas planas, agudas, glabras, de 4,9-13,4 cm x 0,6$2 \mathrm{~mm}$. Panículas laxas, ovadas a elípticas, de 11,9-19,3 x
2,7-3,8 cm, ramas basales, glabras, de 1,8-7,8 cm, desnudas en la base. Pulvínulos anaranjados, glabros. Espiguillas lanceolado-oblongas, verde-oliváceas, 11-15(25)-floras, de 3,8-7 cm x 1-2,2 mm, dispuestas en los ápices de las ramas y no muy abundantes. Pedicelos de 0,5-5 mm, en general más cortos que la espiguilla. Raquilla persistente, glabra. Glumas desiguales, persistentes, linear-lanceoladas, agudas, herbáceas, 1-nervias; la inferior de 1-1,5 x 0,4-0,8 $\mathrm{mm}$; la superior de $1,4-2 \times 0,4-1 \mathrm{~mm}$, nervio escabroso hacia el ápice, márgenes glabros. Lemmas oval-lanceoladas, herbáceas, 3-nervias, de 1,5-2,2 x 1,2-2 mm, glabras, nervio medio y laterales escabrosos hacia el ápice; ápice obtuso. Páleas oblongas, obtusas, membranáceas, de 1,4$2 \times 0,2-0,6 \mathrm{~mm}$, generalmente $3 / 4$ la longitud de la lemma, 
caedizas, superficie intercostal glabras, quillas conspicuas, escabrosas. Lodículas 2, glabras, carnosas. Estambres 3, anteras de 0,2-0,6 mm, algo purpúreas. Cariopsis oblonga a elipsoide, castaño oscura, de 0,5-0,6 x 0,2-0,4 mm, finamente reticulada, mácula embrional igual a la mitad de su longitud, sin surco ventral.

CARACTERES DiAgnósticos: Espiguillas lanceolado-oblongas, 11-15(25)-floras. Lemmas glabras y páleas membranáceas.

Distribución y HÁBItat. Especie nativa de Asia y África. En América está naturalizada, creciendo en Estados Unidos, México, Belice, Guatemala, Nicaragua, Venezuela, Perú, Bolivia y Chile. En Chile crece sólo en la Isla de Pascua.

Especímenes examinados: Región de Valparaíso, Prov. Valparaíso, Isla de Pascua, IV-1911. Fuentes s.n. (SGO)*; Rano Aroi, 23-29-V-1971. Sudzuki 651 (SGO)*; Koe Koe, costa sur, 100 m, VII-1981. Etienne s.n. (CONC)*; Vaitea, near road at the buildings, 13-I-1991. Zizka 1541 (CONC)*.

2. Eragrostis attenuata Hitchc., Contr. U.S. Natl. Herb. 24 (8): 340. 1927. TIPO: "collected on sandy slopes of hills about three kilometers back of Mollendo, Peru, November 17, 1923, by A.S. Hitchcock (no. 22424)" [holotipo: US!; isotipo: BAA, US!].

Sporobolus scaber Phil., Fl. Atacam.: 54. 1860. TIPO: Chile, “Prope Cachinal de la Costa 26 4' lat. m., c.1900 p.s.m. primum inveni, deinde ad Hueso parado et alia loca herbosa litoralis partis deserti vidi; optimum caprarum pabulum". R. Philippi 118 [holotipo: SGO 45543!; isotipo: BAA-2928 (fragm.), US-2891484 (fragm)].

Iconografía: Fig. 7.

Plantas perennes, cespitosas, de 22,6-51,5 cm. Cañas gráciles, erectas o postradas, no ramificadas, nudos y entrenudos glabros. Vainas pilosas, más largas que los entrenudos, de 3,4-6,3 cm, dejando ver los nudos. Lígulas pilosas de 0,6-2 mm, mechones de pelos largos a cada lado de la lígula, pelos de 1,2-1,8 mm. Láminas planas, agudas, de 3,7-7,5 cm x 1-2 mm, pilosas, pelos de base tuberculada, cara adaxial escabrosa. Panículas lineares, contraídas, espiciformes, péndulas, angostas, de 21,6-46,5 x 0,8-4 cm, interruptas en la base, eje glabro, ramas adpresas, cortas, de $0,8-2,4 \mathrm{~cm}$, levemente escabrosas, con espiguillas hasta la base de las ramas. Espiguillas oblongas, violáceas, 37-floras, de 2,5-3,5 x 1-1,2 mm. Pedicelos escabrosos, de 0,6-1,4 mm. Raquilla frágil, levemente ciliada en la base del artejo, articuladas sobre las glumas. Glumas linearlanceoladas, membranáceas, 1-nervias, nervio y márgenes escabrosos, gluma inferior de 0,6-1,2 x 1,2 mm, la superior de 1-1,5 x 0,4 mm, ápice agudo. Lemmas oval-lanceoladas, herbáceas, de 1,4-1,8 x 1-1,5 mm, 3-nervias, nervios laterales conspicuos, escabrosa en toda su superficie, ápice obtuso. Páleas elípticas, herbáceas, caedizas, de 1,2-1,6 x 0,2-0,3 $\mathrm{mm}$, poco menor que las lemmas, quillas escabrosas, ápice obtuso, ciliolado. Estambres 3, anteras anaranjadas de 0,2-0,5 mm. Cariopsis castaño rojiza, lisa, translúcida, elipsoide, de 0,6-0,8 x 0,3-0,4 mm, sin surco ventral, mácula embrional igual a la mitad de su longitud.

Caracteres diagnósticos: Panículas lineares, con el eje glabro. Espiguillas violáceas con glumas de márgenes escabrosos y lemmas oval-lanceoladas.

DistribuCión y HábitAT.- Especie nativa, crece en campos abiertos semidesérticos, en la costa sur del Perú y en Chile en las zonas costeras de la Región de Antofagasta, alrededor de Paposo, en suelos arcillosos.

Especímenes examinados: Región de Antofagasta, Prov. Antofagasta, Taltal, camino entre Paposo y el Rincón, suelo arenoso ripioso con algo de materia orgánica. $60 \mathrm{~m}$. 3-X-1941. Pisano \& Bravo 354 (SGO)*; Paposo, sector Neblineros, 610 m. I-1997. Arancio 10721 (CONC, ULS)*.

3. Eragrostis curvula (Schrad.) Nees, Fl. Afr. Austral. Ill.: 397. 1841. Poa curvula Schrad., Gött. Gel. Anz. 3: 2073. 1821. TIPO: South Africa, Cape province "Hesse s.n. in Herb. Trinius 2327.1 (2327.3)" [holotipo PH; isotipo LE].

Iconografía: Fig. 8.

Plantas perennes, cespitosas, de 64,1-84 cm, muy macolladas, cañas erectas, no ramificadas; nudos y entrenudos glabros. Vainas glabras, más cortas que los entrenudos, abiertas en la zona nodal, de 7-15,8 cm, con pelos largos hacia la zona ligular. Lígulas ciliadas, de 0,8-2 mm, con mechón de pelos de base tuberculada, de 2,5 $\mathrm{mm}$ a ambos lados de la lígula. Láminas filiformes, enangostándose hacia el ápice, de 16-48 cm x 1-2 mm, glabras, agudas. Panículas laxas, ovadas, de 19,7-20 x 2,5$5 \mathrm{~cm}$, libre de espiguillas en la base de las ramas; eje glabro, con manchas glandulares alargadas y hundidas, ramas escabrosas, las basales de 4,8-15 cm. Pulvínulos pilosos. Espiguillas linearlanceoladas, verde-oliváceas, 4-7-floras, de 5,5-9 x 1,2-2 mm. Pedicelos escabrosos, de 1-4 mm. Raquilla persistente, ciliada en la base de los artejos. Glumas linear-lanceoladas, herbáceas, agudas, caedizas, 1-nervias, raro enerve la gluma inferior, márgenes y nervios escabrosos; gluma inferior de 2-2,2 x 0,4 $\mathrm{mm}$; la superior de $3 \times 0,4-0,8 \mathrm{~mm}$. Lemmas oval-lanceoladas, obtusas, herbáceas, de 2,6-3 x 1-1,5 mm, 3-nervias, nervios laterales inconspicuos y glabros, escabrosas. Páleas ovadas, herbáceas, glabras, persistentes, $3 / 4$ de la longitud de la lemma, de 2,4-2,8 x 0,2-0,6 mm, quillas conspicuas, escabrosas en la mitad superior; ápice obtuso redondeado. Lodículas 2, de 0,20,3 mm. Estambres 3, anteras de 1-1,2 mm, castaño-rojizas. 
Cariopsis elipsoide, castaño translúcida, de 1,4-1,6 x 0,6$0,8 \mathrm{~mm}$, sublisa, con surco ventral poco profundo y mácula embrional igual a la mitad de su longitud.

Caracteres diagnósticos: Láminas filiformes. Eje de la panícula con manchas glandulares alargadas y hundidas. Glumas con márgenes y nervios escabrosos. Lemmas escabrosas y páleas herbáceas de $3 / 4$ de la longitud de la lemma.

Distribución y Hábitat.- Especie nativa de África. En América crece en Argentina, Bolivia, Brasil, Chile, Colombia, Costa Rica, Estados Unidos, Uruguay y Venezuela. Esta especie se cultiva en regiones tropicales y subtropicales como forrajera (Nicora 1998). Fue introducida en el oeste de Estados Unidos como controladora de suelos erosionados (Hitchcock 1950). En Chile fue introducida como forrajera de secano en la Provincia de Nuble. Crece en suelos arenosos entre las regiones del Bío-Bío y de Magallanes.

Especímenes examinados: Región de Bío-Bío, Prov. Concepción, cultivada en jardín botánico, 120 m. 9-I-1962. Matthei s.n. (CONC)*; Prov. Bío-Bío, Salto del Laja, 100 m. 29-X-1961. Marticorena 1781 (CONC)*; Región de Magallanes y Antártica Chilena, Prov. Última Esperanza, Punta Arenas. 14-I-1958. Matthei 3660 (CONC)*.

4. Eragrostis kuschelii Skottsb., Ark. Bot., ser. 4 (15): 485. 1963. Eragrostis peruviana var. macranthera Skottsb., Göteborgs Kungl. Vetensk. Samhälles Handl., ser. B, Math. Naturvetensk. Skr. 5(6): 81.1937. TIPO: Chile: "San Ambrosio: 5-6. X.1896. exped. Johow form 3" [holotipo: GB-47761!].

Iconografía: Fig. 9.

Plantas perennes, muy macolladas, cespitosas, de $27-61 \mathrm{~cm}$. Cañas erectas o algo geniculadas en la base, no ramificadas; nudos y entrenudos glabros. Vainas de 3,6-8 cm, más cortas que los entrenudos, a veces mayores pero dejando ver los nudos, pilosas. Lígulas pestañosas, de 0,6-1 $\mathrm{mm}$, rodeadas de un mechón de pelos a ambos lados, pelos de 1,4-1,6 $\mathrm{mm}$. Láminas planas, agudas de 5,2-15,2 cm x 2-6,2 mm, márgenes levemente escabrosos; cara abaxial pilosa, pelos largos de base tuberculada, cara adaxial pilosa y escabrosa. Panículas espiciformes, largamente oblongas, contraídas, de 7-19,2 x 0,6-1,6 cm a veces incluidas en la vaina, eje piloso, ramas cortas, las basales de 0,9-1,7 cm, adpresas. Espiguillas oblongas, verde-oliváceas, 5-7-floras, de 4-5,8 x 1,5-2,2 mm. Pedicelos escabrosos, de 0,3-3 mm. Raquilla persistente, ciliolada en la base del artejo. Glumas lanceoladas, herbáceas, 1-nervias, nervio y superficie dorsal escabrosas, márgenes glabros, la inferior de 1,4-1,8 x 0,4-0,8 mm; gluma superior de 1,8-2,2 x 0,4-1 mm, persistentes, agudas. Lemmas lanceoladas, agudas, levemente mucronadas, herbáceas, de 2,2-2,8 x 1,4-2 mm, escabrosas, 3-nervias, nervios conspicuos. Páleas elípticas, ápice obtuso, $3 / 4$ de la longitud de la lemma, de 1,6-2 x 0,4-0,5 mm, herbáceas, nervios conspicuos escabrosos-ciliolados, cilias de 0,1-0,2 $\mathrm{mm}$, caedizas. Estambres 3, anteras anaranjadas, de 0,2$0,6 \mathrm{~mm}$. Cariopsis oblonga de $0,5-1 \times 0,2-0,5 \mathrm{~mm}$, castaño translúcida, mácula embrional igual a la mitad de su longitud, sin surco ventral.

CARacteres diagnósticos: Lígulas pestañosas. Espiguillas con raquilla persistente. Páleas caedizas con nervios conspicuos, escabrosos-ciliolados.

Distribución y Hábitat. Especie endémica de Chile, crece en arenales y quebradas de la Isla San Ambrosio, al sur de Antofagasta (políticamente Región de Valparaíso). Skottsberg (1963) señala que la especie se encuentra en toda la isla, pero que no es muy abundante. En los faldeos del norte de la isla es escasa, pudiendo encontrarse hasta los $100 \mathrm{~m}$ de altitud, mientras que es frecuente en los pequeños arenales de las planicies y quebradas en el margen sur de la mitad oriental de la isla.

EsPeCímenes eXAminados: Región de Valparaíso, Prov. Valparaíso, Isla San Ambrosio, planicie superior, 21-VIII1960. Bahamonde s.n. (SGO)*; Quebrada Carpa, 330 m, 13IV-1960, Kuschel 15 (SGO)*; Johow 2667 (SGO)*.

5. Eragrostis mexicana (Hornem.) Link subsp. virescens (C. Presl) S. D. Koch \& Sánchez Vega, Phytologia 58 (6): 380. 1985. Eragrostis virescens J. Presl, Reliq. Haenk. 1 (45): 276-277. 1830. Poa virescens (Presl) Kunth, Enum. Pl. 1: 329. 1833. TIPO: Chile, "Hab. in Cordilleris chilensibus". T. Haenke s.n. [holotipo: PR; isotipo: B, BAA-1107!].

Eragrostis chilensis (Moris) Nees, Nova Acta Acad. Caes. Leop. Carol. German. Nat. Cur. 19: Suppl. 1: 32, 1841; 164. 1843. Poa chilensis Moris, Ann. Storia Nat. 4: 60. 1830. TIPO: Chile, "Ann. Nata est in hort. bot. Taurinensi ex seminibus e Chili missis a Bertero" [isotipo: LE, US911928 (fragm.)].

Eragrostis scabra Phil. Fl. Atacam.: 55. 1860. TIPO: Chile, "Prope Paposo in regione fertiliore 500-1000 p.s.m. crescit", R.A. Philippi 1051, Dec 1853 [holotipo: SGO-PHIL-357; isotipo: B, BAA-1089 (fragm.)!, US-556539].

Eragrostis rahmeri Phil., Verz. Antofagasta Pfl.: 88. 1891. TIPO: Chile, "In Quebrada de Guaviña provinciae Tarapacá lecta", G. Rahmer 13.III.1885 [holotipo: SGO 37293!; isotipos: BAA-1081(fragm.), CORD!, SGO 62670!, US].

Iconografía: Fig. 10.

Plantas anuales, cespitosas, de 24-93,5 cm. Cañas gruesas, erectas, ramificadas y algo geniculadas en la base, 1-5-nodes, 
entrenudos y nudos glabros, generalmente con anillo de glándulas bajo los nudos superiores. Vainas de 2,7-11 $\mathrm{cm}$, más cortas que los entrenudos, eglandulosas. Lígulas ciliadas, de 0,4-0,6 mm, mechones con pelos de 1-3 mm a ambos lados de la lígula. Láminas planas, agudas, de 3,2$28,5 \mathrm{~cm} \times 0,2-5,2 \mathrm{~mm}$, eglandulosas, glabras. Panículas elípticas a ovadas, laxas, ascendentes, de $11-31$ x 2,2-15 cm, densamente espiculadas, eje glabros, desarticulación de la espiguilla comenzando en el ápice, ramas basales de 3,5$14,5 \mathrm{~cm}$, alternas y opuestas. Pulvínulos glabros, amarilloanaranjados, algunos ralamente pilosos. Espiguillas linearlanceoladas, verde-oliváceas, 5-10-floras, de 3,8-9 x 0,8$2 \mathrm{~mm}$, no llegan a la base de las ramas, desarticulación comenzando en los antecios basales. Pedicelos escabrosos, de 1-7 mm. Raquilla persistente, ciliada en la base del artejo. Glumas linear-lanceoladas, agudas, violáceas en la madurez, caedizas, herbáceas, carinadas, 1-nervias, nervio y margen escabrosos, la inferior de $0,8-1,8 \times 0,4-0,6 \mathrm{~mm}$, la superior de $1-2,8 \times 0,4-0,8 \mathrm{~mm}$. Lemmas anchamente ovadas, agudas, herbáceas, de 1,2-2,8 x 0,8-1,6 mm, superficie dorsal glabra, 3 -nervias, nervios no conspicuos, levemente escabrosos hacia el ápice. Páleas elípticas, herbáceas, de similar longitud a la lemma, de 0,6-1,8 x $0,3-0,8 \mathrm{~mm}$, persistentes, glabras, quilla escabrosa, escabrosidades de 0,1-0,2 mm, ápice obtuso, finamente ciliolado. Lodículas 2, glabras, casi de 0,2 mm. Estambres 3 , anteras de 0,2-0,4 mm, castaño-rojizas. Cariopsis elipsoide u oblongo, castaño-rojiza, reticulada, de 0,6-1,4 x 0,2-0,8 $\mathrm{mm}$, con surco longitudinal ancho poco profundo, mácula embrional igual a la mitad de su longitud, generalmente rodeada por un halo de coloración verdosa.

CARActeres diagnósticos: Cañas generalmente con anillo de glándulas bajo los nudos superiores. Panículas densamente espiculadas. Lemmas con superficie dorsal glabra y nervios poco conspicuos. Páleas persistentes. Cariopsis con surco longitudinal ancho poco profundo.

\section{Clave para identificar a E. mexicana subsp. virescens de E. mexicana subsp. mexicana.}

1. Espiguillas linear-lanceoladas. Cañas generalmente ramificadas, vainas, láminas, ramas y pedicelos eglandulosos. Panículas con las ramas extendidas o arrimadas al eje.

..E. mexicana subsp. virescens

1'. Espiguillas ovadas a oblongas. Cañas no ramificadas, vainas, láminas, ramas y pedicelos glandulosos. Panículas generalmente con las ramas extendidas

E. mexicana subsp. mexicana

Observaciones: Nicora (1998) no cita a E. virescens J.Presl para la flora de Chile, sin embargo, reconoce los materiales tipo de la especie provenientes del norte del país, además señala a E. scabra Phil. como especie dudosa, basada en materiales colectados en Chile, y menciona su afinidad con E. montufari (Kunth) Steud. Actualmente, E. montufari corresponde a un sinónimo de E. pastoensis (Kunth) Trin., citado para la flora Argentina. E. scabra y E. virescens son reconocidas como un sinónimo de E. mexicana subsp. virescens (Peterson \& Boechat 2001, Zuloaga et al. 2008), por lo cual dicha omisión puede tratarse de una confusión en el traspaso de información.

Distribución y HábitAT: Subespecie sudamericana, habita en Argentina, Perú, Bolivia, Brasil, Chile, Ecuador. En Chile, esta subespecie es el taxón de distribución más amplia, encontrándose desde la Región de Arica y Parinacota hasta la Región de Los Ríos. Crece en sitios eriazos, calles y cultivos escardados, constituye una maleza principal, muy común en suelos modificados (Matthei 1995).

Especímenes examinados: Región de Arica y Parinacota, Prov. Arica, camino Poconchile a Zapahuira, km. 42, 2.300 m. 3-V-1972. Ricardi, Weldt \& Quezada 80 (CONC)*; Azapa. 14-IX-1955. M. Ricardi 3339 (CONC); Quebrada de Vitor Chaca. 22-IX-1955. M. Ricardi 3428 (CONC); Pampa Ossa. Arica la Paz. 2200m. 20-X-1955. M. Ricardi
3435 (CONC); Prov. Parinacota, valle de Azapa, Pampa Algonodal, sector Tignamar- Belén, cultivo de alfalfa. 22III-1987. Matthei \& Rodríguez 353 (CONC); Región de Tarapacá, Prov. Iquique. Guaviña. 13-III-1885. C. Rahmer s.n. (SGO)*; Región de Antofagasta, Prov. El Loa, Oasis de Toconao, quebrada Jere. 2.560 m. 4-IV-1998. Villagrán, Hinojosa \& Latorre 9380 (CONC)*; Toconao. $2.500 \mathrm{~m}$. 7-I-1950. A. Pfister (CONC); suelos arenosos, crece en lugares algo húmedos con suelos arenosos. 18-II-1943. Pisano \& Venturelli 1919 (SGO)*; Región de Atacama, Prov. Huasco, río Chollay, crece en suelo húmedo. $1900 \mathrm{~m}$. 16-I-1994. Arancio, Squeo \& León 94082 (CONC, ULS)*; 28`59'S; 7009'W. 1.500 m. 16-I-1994. Arancio, Squeo \& León 94096 (USL); Camino de Vallenar a Freirina. Llanos de Ferrera. 13-III-1887. Matthei \& Rodríguez 141 (CONC); Prov. Elqui, Rivadavia, cerca de pueblo, camino a Paihuano, en viñedo de 1 a 2 años, terreno arado. 800 m. 12-III-1987. Matthei \& Rodríguez 82 (CONC)*; Guatulame. $30^{\circ} 48^{\prime}$ S; $70^{\circ} 58^{\prime}$ W. 550 m. 20.I.2000. Arancio 12846 (ULS); Río Elqui. 2953'S; $71^{\circ} 15^{\prime} \mathrm{W} .10 \mathrm{~m}$. 18-X2000. Arancio 12999 (ULS); Región de Coquimbo, Prov. Limarí, camino de Combarbalá a Ovalle, Chañaral alto, en las afueras del pueblo. 10-III-1987. Matthei \& Rodríguez 49 (CONC)*; Ovalle, el Palqui, en huertos II-1955. Jiles 2740 (CONC); Caren. 800 m. 19.IX.1927. Barros s.n. (CONC); Región de Valparaíso, Prov. Valparaíso, San Sebastián. 3-I-1965. Acevedo s.n. (SGO; CONC)*; 
Quintero, El Durazno, en una pradera natural. IX-1955. s.c. (CONC); Valparaíso. X.1927. Hunther 30 (SGO)*; Fundo La Vega, cerca de Casablanca, camino de Santiago a Valparaíso 200 m. 28-II-1990. Bobadilla 372 (CONC); Campo cultivado, alrededor de Limache 10-03-1967. Villagrán s.n. (CONC); Limache, en un jardín 15-I-1931. Garaventa s.n. (CONC); Limache, jardín de mi casa. 15-011931. Garaventa 2100 (SGO)*; Quinta Garaventa, crece en las hortalizas 19-II-1939. Looser (CONC); Marga-Marga I-1931. Jaffuel \& Pirión 1849 (CONC); Los Perales I-1911. Jaffuel s.n. (CONC); Prov. Los Andes, entre Los Andes y San Esteban, Los Olmos. 14-XI-1987. Matthei y Quezada 491 (CONC); Región Metropolitana, Prov. Santiago, cerro San Cristóbal. 3-I-1951. Gunckel s.n. (SGO)*; 10-I-1950. Gunckel s.n. (CONC)*; La Platina, en cultivo de porotos. 25-II-2006. Daza \& Nisache 83 (CONC); Quinta Normal s.n. (SGO)*; Macul. XI-1953. Gunckel 25307 (CONC); La Obra. 4-I-1954. Arriagada F. s.n. (CONC); Peñaflor XI1965. Molina s.n. (CONC); Santiago, común en algunas avenidas del cementerio general 3-II-1951. Gunckel s.n. (CONC)*; malezas en algunas calles. XII-1976. Gunckel s.n. (CONC); Calle Las Lilas. 16-V-1954. Navas 1069 (CONC); Apoquindo, a orillas del camino. 10-I-1950. Gunckel s.n. (CONC); Macul. Instituto Pedagógico I-1954. Levi 1795 (CONC); La Florida. 5-V-1958. Abascal 27-49 (CONC); Santiago. Barros 1571 (CONC); Los Cerrillos, maleza en un prado. 5-III-1953. Gunckel s.n. (CONC); El Manzano a orillas del río Maipo. 12-X-1960. Valenzuela V. s.n. (CONC); Quebrada de Macul. XII-1953. Gunckel 42654 (CONC); San José de Lo Arcaya, borde de cultivo de tomates. 540 m. 9-I-1990. Bobadilla 314 (CONC); Lodiges 1863 (SGO)*; Región del Libertador Gral. Bernardo O’Higgins. Prov. Colchagua, río Claro, La Rufina, 1II-1959. Barrientos 2022 (CONC)*; Región del Maule, Prov. Cauquenes, Subestación experimental Cauquenes, INIA, Porvenir, suelo alto. 1-XII-1987. Aravena G-064 (SGO)*; Prov. Talca, Barros Negros, 24-II-1931. Barros 4649 (CONC)*; Prov. Curicó, Rauco (orillas del Teno), 15-I-1923. Barros 1577 (CONC); Predio de la Escuela Hogar No25, en terreno de riego. III-1967. Aravena 326
(SGO)*; Región del Bío Bío, Prov. Ñuble, San Fabián, 3II-1922. Barros 1587 (CONC)*; San Carlos (San Fabián). 2-II-1922. Barros 1595 (CONC); Cobquecura 11-XI-1954. Ledesma 494 (CONC); Chillán, orillas del Lato 21-II1919. Barros 1646 (CONC); Chillán. 1864. Mon. Ant. de Solis s.n. (SGO); Nebuco. 120 m. 16-XI-1987. Silva s.n. (CONC); Prov. Concepción, Río Claro, Fundo Tarpellanca, 3-XII-1961. Matthei 268 (CONC); Prov. Bío-Bío, Monte Águila. Junge 3277 (CONC); Región de La Araucanía, Prov. Cautín, Padre Las Casas, frente al río Cautín, $105 \mathrm{~m}$. Gunckel 15723 (CONC); frente al río Cautín, suelo seco y arenoso, parece ser muy escaso. 26-I-1943. Gunckel s.n. (CONC)*; Temuco. 10-XI-1947. Gunckel 36411 (CONC); Quinta Krause. 22-II-1941. Gunckel 9726-A (CONC); Región de Los Ríos. Prov. Valdivia, Lago Riñihue, en la playa arenosa del lago Riñihue. 160 m. 12-II-1933. Gunckel 5819 (CONC)*; 12-II-1933. Gunckel s.n. (CONC).

6. Eragrostis nigricans (Kunth) Steud., Nomencl. Bot. (ed. 2) 1:563. 1840. Poa nigricans Kunth, Nov. Gen. Sp. 1: 159. 1815.: Ecuador, "Crescit cum proecedente prope Conocoto, Chillo et Sangolqui, Floret Aprili, Majo"

Plantas anuales, cespitosas. Cañas con nudos y entrenudos glabros. Vainas glabras, más cortas que los entrenudos, frecuentemente con glándulas sobre el nervio medio. Lígulas ciliadas, de 0,4-0,8 mm. Láminas planas, agudas, glabras, frecuentemente con glándulas sobre el nervio medio. Panículas laxas o contraídas, densamente espiculadas, ovadas, eje glabro; ramas ascendentes, escabrosas. Pulvínulos glabros. Espiguillas 3-10-floras, violáceas. Pedicelos escabrosos, violáceos. Raquilla conspicua, persistente. Glumas herbáceas, agudas, 1-nervias, nervios escabrosos, caedizas. Lemmas obtusas, herbáceas, 3nervias. Páleas elípticas, herbáceas, glabras con quillas escabrosas, ápice obtuso y ciliolado. Estambres 3, anteras de 0,1-0,5 mm. Cariopsis oblonga, reticulada, de 0,6-1 x 0,2-0,5 mm, castaño rojiza u obscura, con surco ventral ancho poco profundo. Mácula embrional menor a la mitad de su longitud.

1. Plantas de 3,4-28,6 cm. Cañas erectas. Inflorescencias laxas, ramas basales de la inflorescencia de $3,4-10,1 \mathrm{~cm}$, con espiguillas apicales, 3-7 antecios. Páleas caedizas..... E. nigricans var. nigricans

1. Plantas de 5,6-19,5 cm. Cañas decumbentes. Inflorescencias contraídas, ramas basales de la inflorescencia de 1-2,4 cm, con espiguillas hasta la base de las ramas, 5-10 antecios. Páleas persistentes. E. nigricans var. punensis

6.a. Eragrostis nigricans var. nigricans (Kunth) Steud., Nomencl. Bot. (ed. 2) 1: 563. 1840. Poa nigricans Kunth, Nov. Gen. Sp. 1: 159. 1815. TIPO: Ecuador, "Crescit cum proecedente prope Conocoto, Chillo et Sangolqui, Floret Aprili, Majo", Humboldt \& Bonpland s.n. [holotipo: PBonpl; isotipo: BAA-2281 (fragm.)].

Eragrostis subatra Jedwabn., Bot. Arch. 5 (3-4): 202. 1924.
TIPO: "Bolivia, prope La Paz (Rusby nr. 80)", M. Bang 80. 1889 [isotipo: K, US-822065].

Eragrostis tristis Jedwabn., Bot. Arch. 5(3-4): 205. 1924. Eragrostis nigricans var. tristis (Jedwabn.) Pilg., Notizbl. Bot. Gart. Berlin-Dahlem 11: 778. 1933. TIPO: "Bolivia, ad Huancapamba (Pflanz nr. 359), Quechisla (Bender nr. 19); Peruvia, prope Tacna (Meyen)" [isosintipo: BAA-1101]. 
Iconografía: Fig. 11.

Plantas de 7,4-28,6 cm. Cañas erectas, no ramificadas. Vainas glabras, de 0,9-3,8 cm. Láminas de 1,7-10 cm x 1,5-2,2 mm. Panículas laxas, poco numerosas, anchamente ovadas, de 3,4-10,1 x 0,8-4,5 cm, desarticulación de las espiguillas comenzando desde la base, frecuentemente con glándulas, ramas flexuosas, escabrosas, las basales de 0,9-4,5 cm, con espiguillas apicales. Espiguillas linearlanceoladas a lanceoladas, violáceas, 3-7-floras, de 3,4-7 x 0,8-1,8 mm, desarticulación de los antecios comenzando en el ápice. Glumas lanceoladas a oval-lanceoladas, la inferior de $1-2,2$ × $0,4-0,8 \mathrm{~mm}$; la superior de $1,2-2 \times 0,6-1,0 \mathrm{~mm}$. Lemmas oval-lanceoladas, de 1,6-2,4 x 0,8-2,0 mm, nervios laterales inconspicuos, escabrosos desde la mitad al ápice. Páleas caedizas, de similar longitud que la lemma, de 1,4-2 x 0,2-0,4 mm.

Caracteres diagnósticos: Cañas erectas. Espiguillas principalmente apicales, violáceas, 3-7-floras, con lemmas con nervios laterales inconspicuos y escabrosos. Páleas caedizas.

DistribuCión y HÁBITAT: Crece en zonas montañosas, entre los 2.600 y $3.800 \mathrm{~m}$ de altitud, en laderas pedregosas y suelos arenosos desde la Región de Arica y Parinacota a Antofagasta. En Sudamérica habita en Ecuador, Perú, Bolivia, Argentina y Chile. Crece en campos abiertos, pastizales y bordes de caminos y campos de cultivo abandonados (Tovar 1993).

Especímenes examinados: Región de Arica-Parinacota, Prov. Parinacota, camino al portezuelo de Chapiquiña, $2.600 \mathrm{~m}$, 24-III-1961, Ricardi, Marticorena \& Matthei 65 (CONC); Socoroma, en el pueblo, 3.000 m. 05-V-1972. Ricardi, Weldt \& Quezada 148 (SGO, CONC)*; cerca de Putre. $3.300 \mathrm{~m}$. 2-III-1984. Arroyo 84-583/A (CONC) ${ }^{*}$; Prov. Arica, camino Poconchile a Zapahuira, km 48. 2.400 m. 03-05-1972. Ricardi, Weldt \& Quezada 94 (CONC); 71 km E of Arica on HWY 11 towards Putre. Rocky slopes and along quebrada with Atriplex and Ambrosia, 18 27'38,2'"S; 69 47'46,4'W. 2.276 m. 31-III-2001. Peterson \& Soreng 15685 (CONC); $92 \mathrm{~km}$. E de Arica on NWY 11 towards Putre, rocky slopes and drainages with Atriplex, Plantago and Lepidium. $18^{\circ} 22^{\prime} 44,7^{\prime \prime} \mathrm{S} ; 6^{\circ} 38^{\prime} 21,7^{\prime \prime} \mathrm{W} .3 .100 .1$-IV-2001. Peterson \& Soreng 15694 (CONC); Región de Tarapacá, Prov. Iquique, quebrada de Tana, $69 \mathrm{~km}$ from the Panamericana towards Camiña (23km above Calatambo and $3 \mathrm{~km}$ below Camiña) steep rocky gravelly slopes almost devoid of perennial vegetation. $19^{\circ} 19^{\prime} 19^{\prime \prime} \mathrm{S}$; 69²6,74’W. 2.320 m. 28-II-1997. Eggli, Leuenberger \& Arroyo Leuenberger 2785 (CONC); Región de Antofagasta, Prov. El Loa, San Pedro de Atacama, Guatín, cruce de los ríos Puritana y Purifica, 3140 m. 31-III2001. Ackermann 246 (SGO)*; Socaire, suelo arenoso. 3.000 m. 21-II-1943. Pisano \& Venturelli 1959 (SGO)*; $3.500 \mathrm{~m}$. V-1957. Munizaga 31014 (CONC)*; $14 \mathrm{~km}$ al N de Socaire, a los pies del cerro entrando al Salar de Atacama. $2580 \mathrm{~m}$. 8-V-1997. Rodríguez y. Ruiz 3746 (CONC); Peine, suelo arenoso, crece entre las piedras en lugares secos. $2.800 \mathrm{~m}$. 21-II-1943. Pisano \& Venturelli 1923 (SGO)*.

6.b. Eragrostis nigricans var. punensis Nicora, Boissiera 54: 65. 1998. TIPO: "Argentina. Prov. Jujuy, Dpto. Tumbaya: subida de Purmamarca al Abra de Pives, $3800 \mathrm{~m}$, 24.IV.1975, Cabrera, A.L. \& al. 26382" [holotipo: SI!].

Iconografía: Fig. 12.

Plantas de 5,6-19,5 cm. Cañas decumbentes en la base, frecuentemente ramificadas, a veces con glándulas bajo los nudos. Vainas de 1,4-2,5 cm. Láminas de 1,3-3,3 cm x 1,5-2,2 mm. Panículas contraídas, múltiples, de 3,2-6,5 x 0,7-3,5 cm, desarticulación de las espiguillas comenzando en el ápice; ramas con espiguillas hasta su base, las basales de 1-2,4 cm, a veces con manchas glandulares. Espiguillas lineares a linear-lanceoladas, violáceas en la madurez, 510-floras, de 4-9 x 1-2 mm. Pedicelos violáceos oscuros, de $0,5-2,5 \mathrm{~mm}$, a veces con manchas glandulares. Glumas linear-lanceoladas, violáceas, gluma inferior de 1,2-1,8 x $0,4 \mathrm{~mm}$, gluma superior de $1,6-2 \times 0,6-0,8 \mathrm{~mm}$. Lemmas lanceoladas, de 2-2,4 x 0,8-2 mm, superficie dorsal glabra con nervios escabrosos, los laterales conspicuos, márgenes escabrosos. Páleas persistentes, $3 / 4$ de la longitud de la lemma, de 1,6-2 x 0,3-0,4 mm.

Caracteres diagnósticos: Cañas decumbentes en la base. Ramas de la inflorescencia con espiguillas hasta su base, frecuentemente con manchas glandulares y espiguillas con páleas persistentes.

Distribución y HÁbitat: Especie endémica del Altiplano de Chile y Argentina, entre los 2.950 y $3.800 \mathrm{~m}$. En Chile crece en las regiones de Arica y Parinacota y de Antofagasta, en suelos arenoso-pedregosos, formando champas.

Especímenes examinados: Región de Arica-Parinacota, Prov. Parinacota, camino al Portezuelo de Chapiquiña, a 40 km de Arica. 2.850 m. 25-III-1961. Ricardi, Marticorena \& Matthei 93 (CONC)*; Región de Antofagasta, Prov. El Loa, Socaire, suelo arenoso. 3.000 m. 22-II-1943. Pisano \& Venturelli 1957 (SGO)*; tolar de Fabiana ramulosa. 3.400 m. 5-7- IV-1997. S. Teillier 4020 (CONC; SGO)*; Camino a baños de Puritama a San Pedro de Atacama, km 18 , en el fondo de quebrada pedregosa. $3.300 \mathrm{~m}$. 14-V1972. Ricardi, Weldt \& Quezada 392 (CONC)*; camino de San Pedro de Atacama a Puritana. 2.820 m. 13-IV-1997. Arroyo, Cavieres \& Humaña 97537 (CONC)*. 
7. Eragrostis peruviana (Jacq.) Trin., Mém. Acad. Imp. Sci. St. Pétersbourg, ser. 6. Sci. Math. 1: 396. 1830. Poa peruviana Jacq., Collectanea 1: 107. 1787. TIPO: "Perú, N.J. von Jacquin" [holotipo: desconocido; isotipo: US-fragm].

Eragrostis deserticola Phil., Fl. Atacam.: 55. 1860. TIPO: Chile "Circa Hueso parado, 2526' lat. m. et 1200 p.s. m. inveni" R.A. Philippi 358 [holotipo: SGO 63542!; isotipos: BAA, SGO-63452!, US-556537].

Eragrostis peruviana (Jacq.) Trin. var. brachythyrsus Pilg., Bot. Jahrb. Syst. 37: 375. 1906.

TIPO: "Peru: Mollendo, in formatione »Loma« dicta, 200600 m s. m. (Weberbauer n.1462 - mense Octobri 1902)" [holotipo: B (designado por Nicora 1994)].

Iconografía: Fig. 13.

Plantas anuales, cespitosas, de 11,1-29,3 cm. Cañas erectas, no ramificadas, nudos y entrenudos glabros, 2-5 entrenudos largos. Vainas de 1,9-4,6 cm, más cortas que los entrenudos, pilosas, pelos de base tuberculada. Lígulas pilosas de 0,4-1,2 $\mathrm{mm}$, mechón de pelos largos de 1,5 mm a ambos costados. Láminas planas a involutas, acuminadas, de 2,6-9,2 cm x 1-4,6 mm, pilosas, pelos de base tuberculada, margen escabroso. Panículas contraídas, espiciformes, anchamente oblongas, de 1,9-23,2 x 0,8-1,4 cm, eje piloso; ramas cortas, adpresas, escabrosas, las basales de 0,4-1 cm, con espiguillas hasta la base. Espiguillas oblongas, 3-7(9)-floras, oliváceas, pajizas a la madurez, de 1,2-4,6 x 1,2-3,2 mm. Pedicelos levemente escabrosos, de 0,1-1,2 mm. Raquilla frágil, ciliada en la base del artejo, artejos de 0,3-0,4 mm. Glumas lanceoladas, agudas, herbáceas, caedizas, 1-nervias, nervio escabroso, con márgenes ciliolados, gluma inferior de 1,3-1,6 x 0,6-0,8 mm; la superior de 1,4-2 x 0,8-1,2 mm. Lemmas lanceoladas, herbáceas, agudas, mucronuladas, de 1,8-2,4 x 1-1,8 mm, 3-nervias, nervios laterales conspicuos, escabrosos, al igual que toda la superficie dorsal, margen finamente ciliolado. Páleas elípticas, herbáceas, de 1,2$1,8 \times 0,2-0,4 \mathrm{~mm}$, alrededor de $2 / 3$ del largo de la lemma, persistentes, ápice obtuso, ciliolado; quillas ciliadas, cilios de 0,2-0,6 mm. Estambres 3, anteras amarillo-pálidas, de 0,2-0,3 mm. Cariopsis globosa o elipsoide, castaño-rojiza, lisa, de 0,5-0,8 x 0,2-0,4 mm, sin surco ventral, mácula embrional 1/3 del largo del fruto. Pericarpio se desprende con facilidad.

Caracteres Diagnósticos: Plantas anuales. Lígulas pilosas. Láminas con ápices acuminados. Espiguillas con glumas con márgenes ciliolados y páleas persistentes con quillas ciliadas. Mácula embrional 1/3 del largo de la cariopsis.

Distribución y HÁBITAT: En Chile habita la zona costera de Paposo al sur (Región de Antofagasta), incluyendo el territorio insular, en las Islas Desventuradas, Región de
Valparaíso. Kuschel (Skottsberg 1963) señala que esta especie es muy común en la isla, sobre todo en los fondos de quebradas donde alcanza los $50 \mathrm{~cm}$ de altura, siendo más escasa en los faldeos. Tanto esta especie como E. kuschelii, son frecuentes en los arenales y quebradas en el margen sur de la mitad oriental de la isla (Skottsberg 1963). También crece en Perú, en la costa centro-sur, en campos abiertos de suelos arenosos.

Comentarios: Nicora (1998) cita para la Región de Arica y Parinacota a E. peruviana, Ricardi et al. 121 (CTES), sin embargo, este material concuerda con la información de la etiqueta del ejemplar Ricardi et al. 121 (CONC), correspondiente a $E$. weberbaueri, difiriendo sólo en el mes de colecta, razón por la cual podría tratarse de un error en los datos, con lo cual no hay registros de E. peruviana en esta región.

Especímenes examinados: Región de Antofagasta, Prov. Antofagasta, camino entre Paposo y El Rincón, entre 5 y 10 km al N de Paposo. 60 m. 3-X-1941. Pisano \& Bravo 350 (CONC)*; Paposo, quebrada la higuera. 500 m. 26-IX1953. Ricardi, Weldt \& Quezada 2667 (CONC)*; Quebrada el Cardón, en punta de Plata, al $\mathrm{N}$ de Paposo, suelo arenoso rocoso. En lugares secos. $30 \mathrm{~m}$. 10-X-1941. Pisano \& Bravo 431 (CONC); Quebrada el Médano al N de Paposo, suelo arenoso, en los faldeos. $450 \mathrm{~m}$. 8-X-1941. Pisano \& Bravo 391 (CONC); Circa de Hueso Parado. 25²6'S, 1200 m. R.A. Philippi 358 (SGO); Región de Valparaíso. Prov. Valparaíso, Islas Desventuradas, Isla San Ambrosio. X-1950. Juan González. 19068 (CONC)*; Quebrada Carpa. 330 m. 13-XI-1960. Kuschel (SGO)*; 1896. Johow 2865 (SGO); planicie superior 21-VIII-1960. Bahamondes (SGO)*; Isla San Félix. Sector aledaño a pista de aterrizaje, costado E, acercándose a la Base. Zona de nidificación. $26^{\circ} 17^{\prime} \mathrm{S}$; $80^{\circ} 07^{\prime}$ W. 22-X-2000. Cuvertino S. (SGO)*; 80 m. 29-XII1989. Hoffmann SF3 (CONC).

8. Eragrostis pilosa (L.) P. Beauv., Ess. Agrostogr.: 71, 162, 175. 1812. Poa pilosa L., Sp. P1. 1: 68. 1753. TIPO: "Habitat in Italia" [epitipo B (designado por Scholz en Cafferty et al., 2000)].

Iconografía: Fig. 14.

Plantas anuales, cespitosas, de 10,1-74,5 cm. Cañas erectas, algo geniculadas en la base, nudos y entrenudos glabros. Vainas más cortas que los entrenudos, glabras, de 1,9-10,6 $\mathrm{cm}$, con márgenes escabrosos, acentuándose hacia la lígula. Lígulas pilosas, de 0,3-0,6 mm, mechón de pelos largos a ambos costados. Láminas planas a involutas, de 2,3-15,8 cm x 1,6-4 mm, glabras, agudas. Panículas laxas, ovadas, flexuosas, de 6,6-31 x 2,5-8 cm, múltiples ejes floríferos, glabros, densamente espiculadas; ramas ascendentes, 
escabrosas, las basales de 3-11,5 cm, desarticulación de las espiguillas desde el ápice a la base. Pulvínulos castañooscuros, pilosos, pelos de hasta $3 \mathrm{~mm}$. Espiguillas linearlanceoladas, 6-9-floras, verde-oliváceas, de 3,2-6 x 0,8-1,4 $\mathrm{mm}$, desarticulación de los antecios comenzando en la base. Pedicelos largos, de 0,8-9 mm. Raquilla persistente, glabra. Glumas lanceoladas, obtusas, desiguales, herbáceas, caedizas, la inferior enerve o 1-nervia, de 0,4-1,4 x 0,2-0,5 $\mathrm{mm}$, la superior 1-nervia, de 1-2 x 0,5-0,6 mm. Lemmas ovadas, agudas, herbáceas, de 1,4-2 x 0,8-1,2 mm, 3-nervias, nervios escabrosos hacia el ápice, los laterales conspicuos, márgenes glabros. Páleas elípticas, de 1-1,6 x 0,2-0,4 mm, ápice obtuso y finamente ciliolado, herbáceas, normalmente $3 / 4$ de la longitud de la lemma, glabras, quillas escabrosas, caedizas. Estambres, 3, anteras, rojizas, de 0,2-0,3 $\mathrm{mm}$. Cariopsis castaño-clara, finamente reticulada, oblongo, de 0,6-1 x 0,3-0,5 mm, mácula embrional igual a la mitad de su largo, sin surco ventral.

Caracteres diagnósticos: Vainas más cortas que los entrenudos. Lígulas pilosas. Espiguillas con glumas obtusas y lemmas con nervios escabrosos hacia el ápice, los laterales conspicuos. Cariopsis sin surco ventral.

Distribución y HÁbitat: Especie originaria de Europa, cosmopolita, habita regiones templadas, subtropicales y tropicales, hasta los $2.500 \mathrm{~m}$. Introducida en América, en nuestro país es escasa y sólo se la ha encontrado en algunos valles de la regiones de Coquimbo, Maule y Metropolitana.

Especímenes examinados: Región de Coquimbo, Prov. Choapa, Illapel 14. Joseph 4642 (SGO)* Región de Valparaíso, Prov. Valparaíso, Itahue, orilla del Río Claro, Fundo El Colorado, 230 m. 2-II-1952, CONC 67572*; Región Metropolitana, Prov. Cordillera, fundo San José, frente al puente El Quilal. 510 m. 24-IV-1986. Araya 118 (CONC); Región del Maule, Prov. Curicó, Molina y Barros 1578 (CONC)*.

9. Eragrostis polytricha Nees, Fl. Bras. Enum. Pl. 2: 507508. 1829. Poa polytricha (Nees) Kunth, Enum. Pl. 1: 331. 1833. TIPO: "Habitat in Brasili australia australi, Sellowvidi in herb. Reg. Berol.-B in campis limosis altis prope Villa Rica aliisque locis provinciae Minarum" [holotipo: B; isotipos: BAA-2668 (ex B), US-77386 (fragm.)].

Iconografía: Fig. 15.

Plantas perennes, cespitosas, de 22,7-67 cm. Cañas erectas, no ramificadas, nudos y entrenudos glabros. Vainas más largas que los entrenudos, de $3-13 \mathrm{~cm}$, pilosas, pelos de base tuberculada. Lígulas ciliadas, de 0,1-0,6 mm, con pelos de 1-2 $\mathrm{mm}$ a ambos lados de la lígula. Láminas planas, acuminadas, de $6,7-24,7 \mathrm{~cm} \times 2-4 \mathrm{~mm}$, pilosas, pelos de base tuberculada. Panículas laxas, abiertas, ovadas a piramidales, verde-oliváceas, de 14,5-34,2 x 8,9-19,5 cm, generalmente con 1 eje florífero, glabro y algo sinuoso hacia el ápice; ramas extendidas, escabrosas, las basales de 9,319,2 × $3 \mathrm{~cm}$, nudos basales con 3-5 ramas generalmente acompañados por un mechón de pelos largos y transparentes de 2-4 mm. Pulvínulos pilosos, pelos de $2 \mathrm{~mm}$. Espiguillas 3-7-floras, lanceoladas, violáceo-negruzcas, de 3-6,2 x 1$2 \mathrm{~mm}$, dispuestas en la mitad superior de las ramas, poco abundantes. Pedicelos levemente escabrosos, de 1-10 mm, más largos o más cortos que las espiguillas. Raquilla frágil, escabrosa. Glumas ovado-lanceoladas, glabras, herbáceas, hialinas, caedizas, 1-nervia, nervios y márgenes escabrosos hacia el ápice, agudas, gluma inferior de 1-1,6 x 0,20,7 mm; gluma superior de 1,2-2,2 x 0,3-1 mm. Lemmas anchamente ovadas, agudas, herbáceas, con margen hialino, glabras, de 1,6-2,2 x 1-1,6 mm, 3-nervias, nervios laterales inconspicuos, nervio medio escabroso hacia el ápice. Páleas elípticas, obtusas, membranáceas, de similar longitud a la lemma, de 1,6-2 x 0,2-0,8 mm, glabras, quillas escabrosas, ápice finamente ciliolado, caedizas. Lodículas 2, glabras, carnosas, casi de 0,4 mm. Estambres 3, anteras de 0,3-0,6 $\mathrm{mm}$, purpúreas. Cariopsis de 0,6-1 x 0,2-0,8 mm, castaño oscura rojiza, cuadrilongo, reticulada, con surco ventral profundo y mácula embrional igual a la mitad de la longitud del fruto.

Caracteres diagnósticos: Vainas más largas que los entrenudos, pilosas. Láminas pilosas. Pulvínulos pilosos. Espiguillas lanceoladas, violáceo-negruzcas, con raquilla frágil. Lemmas anchamente ovadas, páleas membranáceas. Cariopsis cuadrilongo.

Distribución y Hábitat: Especie nativa de América. Crece en suelos arenosos, arcillosos o pedregosos, en campos altos y secos (Nicora 1998). En Chile esta especie es bastante común, creciendo asociada a áreas cultivadas entre las regiones Metropolitana y de Los Ríos.

Especímenes examinados: Región Metropolitana. Prov. Santiago, Conchalí, a orillas de un canal de riego. $550 \mathrm{~m}$. XI1952. Gunckel 41551 (CONC)*; Región del Maule, Prov. Talca, Constitución, en cerros. 15 m. 19-X-1942. Silva \& Jirkal 216 (SGO)*; Región del Bío Bío, Prov. Ñuble, Bureo. 250 m. II-1926. Barros 10291 (CONC); Prov. Concepción, Hualpén, suelo seco debajo de arbustos. 1-I-1941. Gunckel 12896 (CONC); Concepción. IX-1927. Barros s.n. (CONC); Cerro Caracol. 200 m. 8-XII-1941. Pfister 364 (CONC)*; Cerro Caracol, en la segunda quebrada que se orienta NOSE. 60-80 m. 30-XII-1940. Muñoz \& Schick 1507 (SGO)*; Cultivado en Jardín Botánico. 10 m. 9-I-1962. Matthei s.n. (CONC)*; Matthei s.n. (CONC); Prov. Bío-Bío, Río Claro, fundo Tarpellanca, en suelo arenoso. III-1961. Matthei s.n. (CONC)*; entre Yumbel y Salto del Laja. 6-I-1959. 
Marticorena, Mancinelli \& Torres s.n. (CONC); Antuco, km 31 de Los Angeles a Antuco, en potreros arenosos a orillas del camino. 21-XII-1940. Muñoz 1798 (SGO)*; Antuco, cerrito La Virgen. 650 m. 13-I-1941. Junge 6939 (SGO, CONC)*; Alrededores de Antuco, entre las rocas a orillas de camino. 6-I-1942. Muñoz \& Johnson 2748 (SGO)*; Prov. Arauco, Contulmo, cerro. 150 m. 26-XII-1935. Montero 2776 (CONC); Región de la Araucanía. Prov. Malleco, Angol, común en algunos cerros vecinos a Angol, formando colonias. 80 m. 9-I-1942. Gunckel 11998 (CONC)*; Angol, cerro 13-X-1957. Montero 5320 (CONC); Cerros lado S.E. 140 m. 30-XI-1941. Montero 3945 (CONC)*; Prov. Cautín. Pitrufquén. Río Toltén. 93 m. 8-XII-1952. Montero 4588 (CONC); Truf-Truf, en los faldeos de un cerro no muy común 150 m. 10-XII-1947. Gunckel 17087 (CONC); Temuco. Cerro Ñielol. 16-XII-1941. Montero 4513 (CONC)*; Temuco, entre plantas herbáceas. $50 \mathrm{~m}$. X-1944. Gunckel 47768 (CONC); Padre Las Casas. 17-XI1934. Montero 1968 (CONC); Freire. Long Long. $450 \mathrm{~m}$. 17-I-1937. Hollermayer 1262 (SGO, CONC)*; Región de Los Ríos, Prov. Valdivia, Llifen-Lago Ranco. 12-I-1942. Pfister 386 (CONC)*; Valdivia. Puñire, pampa. XII-1927. Hollermayer 18 (CONC); Joseph 4687 (CONC).

10. Eragrostis pycnantha (Phil.) Nicora, Gayana Bot. 51:4. 1994. Poa pycnantha Phil., Anales Univ. Chile 94: 165. 1896. Poa densiflora Phil., nomen nudum. "Prov. Atacama. IX. 1885 Phil. (SGO 37312!)". TIPO: Chile, "Prope Copiapó septembri 1885 a Fr. Philippi lecta est." [holotipo: SGO-Phil 411 !; isotipo: B, BAA-1079, W]

Iconografía: Fig. 16.

Plantas perennes, cespitosas de 13,5-24,2 cm. Cañas erectas, a veces geniculadas en la base, no ramificadas, nudos y entrenudos pilosos, a veces con glándulas irregulares amarillas bajo los nudos. Vainas pilosas, de 2,3-5,3 cm, más largas que los entrenudos, márgenes pilosos. Lígulas pilosas, de 0,6-1 mm. Láminas convolutas, de 1,8-3,5 cm x 0,6-2 mm, pilosas, ápice obtuso. Panículas espiciformes, contraídas, oblongas, verde-oliváceas, de 5,1-7,4 x 0,8-0,9 $\mathrm{cm}$, desarticulación de las espiguillas desde el ápice, eje piloso y escabroso; ramas adpresas, escabrosas y pilosas, las basales de 0,8-1,8 cm. Espiguillas lanceoladas, 3-7-floras, desarticulación de los antecios desde el ápice, de 3,5-4,8 $\mathrm{x}$ 1,5-2,2 mm. Pedicelos pilosos y escabrosos de 0,6-1,5 mm. Raquilla frágil, levemente ciliada en el ápice del artejo. Glumas linear-ovadas, membranáceas, hialinas, la inferior de 1-1,3 x 0,2-0,4 mm; la superior de $2 \times 0,6-0,8 \mathrm{~mm}, 1-$ nervias, nervio y márgenes escabroso-ciliados, agudas. Lemmas lanceoladas, obtusas, herbáceas, de 2-2,2 x 1,6-2 $\mathrm{mm}, 3-(4)$-nervias, superficie dorsal escabrosa y ciliada. Páleas elípticas, herbáceas, escabrosas, de similar longitud a las lemmas, de 1,8-2 x 0,5-0,6 mm, caedizas, ápice agudo y ciliolado, quillas escabroso-ciliadas, cilias de 0,1-0,4 mm. Lodículas 2, bilobuladas, carnosas, glabras, de $0,2 \mathrm{~mm}$. Estambres 3, anteras anaranjadas de 0,2-0,4 $\mathrm{mm}$. Cariopsis oblongas, castaño-rojiza, finamente reticulada, de $0,6-0,8 \mathrm{x}$ 0,3-0,4 mm. Mácula embrional menor a la mitad de su largo, sin surco ventral.

Caracteres diagnósticos: Cañas con nudos y entrenudos pilosos, a veces con glándulas irregulares amarillas bajo los nudos. Láminas convolutas. Espiguillas lanceoladas, glumas con márgenes escabroso-ciliados, lemmas y páleas escabrosas y ciliadas. Cariopsis con mácula embrional menor a la mitad de su largo.

Distribución y Hábitat: Especie endémica de Chile, crece entre arbustos en la costa de la Región de Atacama, a 140 m de altitud, muy escasa.

Especímenes examinados: Región de Atacama, Prov. Huasco. Freirina. Llanos de Carrizalillo, a $4 \mathrm{~km}$ de Carrizalillo hacia Vallenar. 140 m. 24-IX-1941. Muñoz \& Johnson 1982 (SGO)*; s.n. (SGO 37312)*.

11. Eragrostis tenuifolia (A. Rich.) Hochst. ex Steud., Syn. Pl. Glumac. 1: 268. 1854. Poa tenuifolia A. Rich., Tent. Fl. Abyss. 2: 425. 1850. TIPO: "Abyssinia" [sintipos: K, L, W, US-1127147 (fragm)].

Iconografía: Fig. 17.

Plantas perennes, cespitosas, de 30,6-31,4 cm. Cañas erectas, no ramificadas, nudos y entrenudos glabros. Vainas aquilladas, glabras, de 9,6-10,4 cm, mayores que los entrenudos. Lígulas ciliadas, de 0,2 mm, mechón de pelos a ambos costados, pelos de hasta $0,8 \mathrm{~mm}$. Láminas planas a convolutas, de $5,6 \mathrm{~cm} \times 1 \mathrm{~mm}$, glabras, agudas. Panículas laxas, verde-oliváceas, de 11,4-13,1 x 3,1-4,4 $\mathrm{cm}$, desarticulación de las espiguillas comenzando en el ápice, eje glabro, ramas extendidas, las basales de 3,5-3,7 $\mathrm{cm}$, espiguillas distribuidas en el ápice de éstas. Pulvínulos pilosos, pelos de hasta 1,6 mm, color marrón. Espiguillas lineares, verde oliváceas con base blanquecina, 5-10(12)floras, de 4,4-6 x 1,4-1,6 mm. Pedicelos largos, delgados y flexuosos, de 4,5-7 mm. Raquilla persistente, finamente escabrosa en la base del artejo, antecios muy arrimados a la raquilla. Glumas lanceoladas, herbáceas, caedizas, desiguales, la inferior de $0,6-0,8 \times 0,2-0,4 \mathrm{~mm}$; la superior de $0,8-1,2 \times 0,4-0,5 \mathrm{~mm}$, enerves o 1 -nervias, insertas a distinta altura dejando un entrenudo visible, agudas. Lemmas oblongas, agudas, más firmes que las glumas, herbáceas, de 1,8-2,0 x $1 \mathrm{~mm}, 3$-nervias, nervio medio escabroso hacia el ápice y los laterales poco visibles, glabros. Páleas elípticas, herbáceas, glabras, ápice obtuso ciliolado, similar en longitud a la lemma, de 1,4-1,6 x 0,2-0,4 mm; quilla 
conspicua, levemente escabrosa, persistentes. Estambres 3, anteras anaranjadas de $0,4 \mathrm{~mm}$. Cariopsis ovada, de $1 \times 0,6$ $\mathrm{mm}$, muy comprimida lateralmente, castaño-translúcida, finamente reticulada, mácula embrional igual a la mitad de su largo, con surco ventral poco profundo y angosto.

CARACTERES diagnósticos: Espiguillas lineares, con glumas lanceoladas y páleas persistentes, herbáceas. Cariopsis ovadas muy comprimidas lateralmente.

DistribuCión y HÁBITAT: Descrita originalmente para Abisinia, es una maleza que vive en África Tropical y Madagascar, India, Nueva Guinea, Australia y Sudamérica (Nicora 1998). Si bien tiene una amplia distribución en Sudamérica, en Chile sólo se la ha recolectado en Isla de Pascua.

Especímenes examinados: Región de Valparaíso, Prov. Isla de Pascua, Cráter Rano Raraku. 12-V-1994. Lücke 10 (CONC)*.

12. Eragrostis weberbaueri Pilg., Bot. Jahrb. Syst. 37: 375. 1906. TIPO: "Perú: Depart. Ancachs, inter Samanco et Caraz infra Pampa Romas, in formatione aperta, praecipue gramina gerente intermixtis fruticibus et Cactaceis, $2300 \mathrm{~m}$. s. m. (Weberbauer N. 3189 - fructifera mense Majo 1903)" [holotipo: B; isotipo: BAA-1100!; US-2767411].

Iconografía: Fig. 18.

Plantas perennes, cespitosas, de 6,5-33,6 cm. Cañas glabras, erectas, a veces geniculadas en la base, no ramificadas, nudos pilosos, pelos de 1,2-1,8 mm, glándulas irregulares, amarillo limón bajo los nudos. Vainas de 1,1-6 cm, pilosas hacia la lígula, margen piloso, pelos largos blancos, más cortas que los entrenudos. Lígulas pilosas, de 0,6-1,5 mm. Láminas convolutas, obtusas, pilosas, de 1,4-7,5 $\mathrm{cm} \times 0,4-6 \mathrm{~mm}$. Panículas contraídas, oblongas, espiciformes, interruptas en la base, oliváceas, de 2,6-10,5 x 0,5-1,5 cm, eje escabroso y piloso, ramas cortas, adpresas, pilosas, las basales de 0,6-2 cm, llevando espiguillas hasta su base. Espiguillas oblongas, verde-oliváceas, (4)11-15-floras, de 3-8 x 1-2,4 $\mathrm{mm}$. Pedicelos levemente escabrosos, violáceos, de 0,2-2,6 $\mathrm{mm}$. Raquilla frágil, con cilios en la base del artejo. Glumas linear-lanceoladas, obtusas, membranáceas, caedizas, gluma inferior de 1-2 x 0,2-0,4 mm; gluma superior de 1,6$2,2 \times 0,8 \mathrm{~mm}, 1$-nervias, nervios escabrosos hacia el ápice, obtusas, márgenes glabros, ápice denticulado. Lemmas lanceoladas, agudas, más firmes que las glumas, herbáceas, de 2-2,8 x 0,8-2,4 mm, superficie dorsal escabrosa, 3-(5)nervias, nervios conspicuos y escabrosos, ápice bilobulado y mucronado. Páleas persistentes, elípticas, herbáceas, de 1-1,6 x 0,2-0,4 mm, 3/4 de la longitud de la lemma, ápice agudo, ciliolado, quillas escabrosas. Estambres 3, anteras amarillo-pálido, de 0,3-0,5 mm. Cariopsis oblonga, de 0,6-1 x 0,2-0,4 mm, castaño translúcida, lisa. Mácula embrional igual a la mitad de su longitud, rodeada por un halo verde oscuro. Surco ventral ausente.

Caracteres diagnósticos: Cañas con nudos pilosos, y glándulas irregulares, de color amarillo-limón bajo éstos. Láminas convolutas. Espiguillas con glumas con ápice denticulado.

DistRIBUCIÓN Y HÁBITAT: Especie nativa de las altas montañas de la Cordillera de los Andes de Perú y norte de Chile; crece en campos abiertos, con pastizales, en suelos arenosos y secos o en áreas de cultivos. En Chile crece desde los 2.100 a $3.700 \mathrm{~m}$ de altitud, en las regiones de Arica-Parinacota y de Antofagasta.

Especímenes eXaminados: Región de Arica-Parinacota, Prov. Arica, camino de Poconchile a Zapahuira, km 41. 2.100 m. 3-V-1972. Ricardi, Weldt \& Quezada 59 (CONC)*; Camino Poconchile a Putre, $7 \mathrm{~km}$ antes de Zapahuira 3.200 m. 4-V-1972. Ricardi, Weldt \& Quezada 121 (CONC)*; Camino Poconchile a Zapahuira, km. 48. 2.400 m. 3-V1972. Ricardi, Weldt \& Quezada 95a (CONC)*; Camino de Arica al Portezuelo de Chapiquiña, km.93, 3.350 m. 8II-1964. Marticorena, Matthei \& Quezada 18 (CONC)*; FFCC de Arica La Paz. Puquios. Km. 108-106, 3.600-3.700 m. 27-XI-1955. Ricardi 3541 (CONC)*; Prov. Parinacota, camino entre Putre y Socoroma, km. 16, 3.460 m. 21-III1987. Matthei \& Rodríguez 300 (CONC); Camino entre Zapahuira y Arica. Pampa Mala humaña, 3.160 m. 21-III1987. Matthei \& Rodríguez 315 (CONC); cercanías de Putre 3-IV-2002. Muñoz s.n. (SGO)*; Belén, Pampa chuño. 3.180 m. 23-V-2000. Belmonte 20194 (CONC)*; $71 \mathrm{~km}$. E. of Arica on HWY 11 towards Putre. Rocky slopes and along quebrada with Atriplex and Ambrosia 18 $27^{\circ} 38,2$ "S; $69^{\circ} 47^{\prime} 46.4^{\prime \prime} \mathrm{W} 2.276$ m. 31-III-2001. Peterson \& Soreng 15684 (CONC)*; $92 \mathrm{~km}$. E. of Arica on HWY 11 towards Putre. Rocky slopes and drainages with Atriplex, Plantago y Lepidium 18²2'44.7's; 69³8'21.7' W 3.100 m. 1IV-2001. Peterson \& Soreng 15693 (CONC)*; Región de Antofagasta, Prov. El Loa, alrededores de Toconce, terrazas de cultivo, chacra de Rosa Cruz. 3.300 m. 26-I-1980. Villagrán \& Armesto 2294 (CONC, SGO)*. 


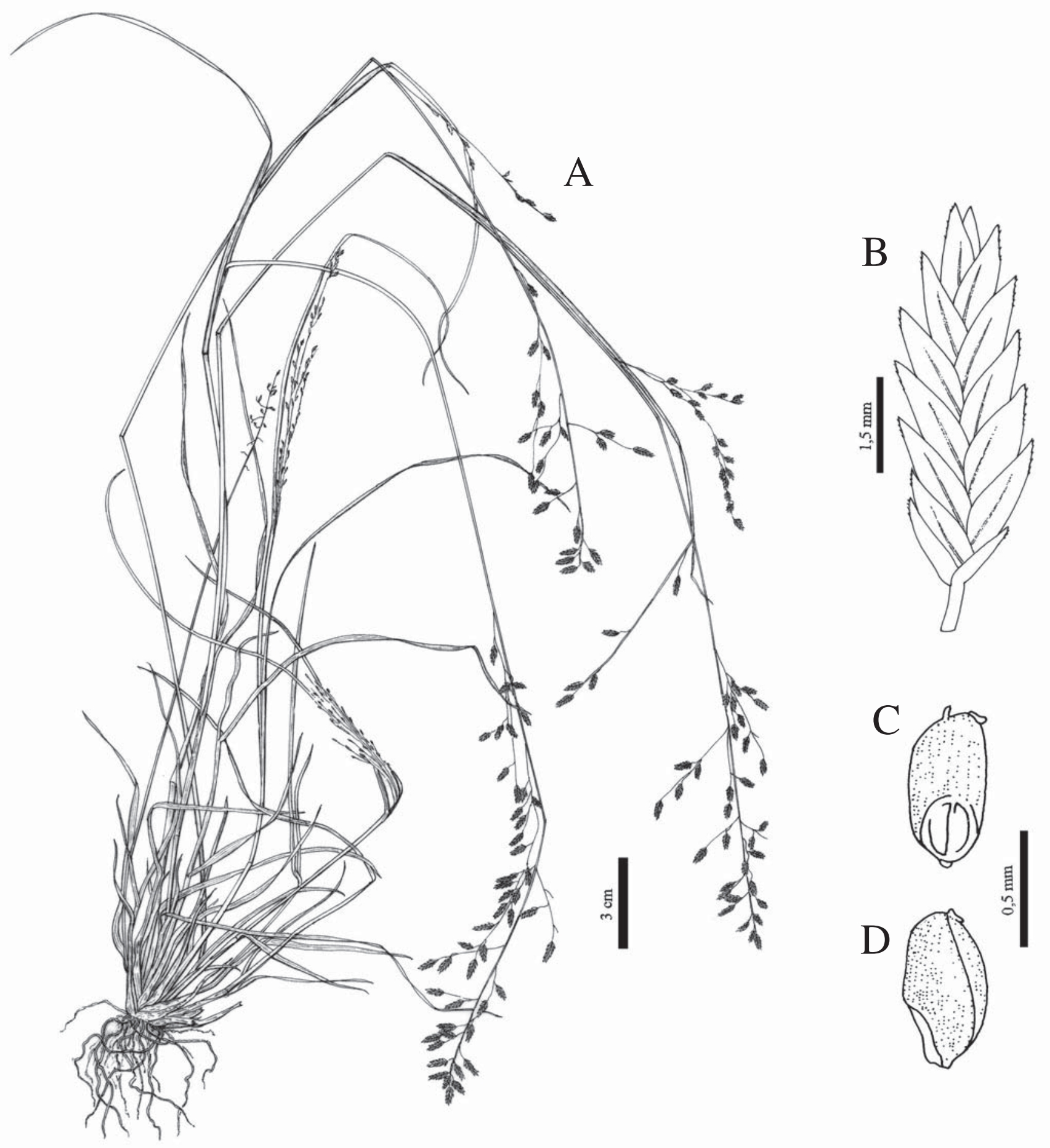

FIGURA 6. Eragrostis atrovirens (Desf.) Trin. ex Steud., Zizka 1541 (CONC 110022). A. Hábito; B. Espiguilla; C y D. Cariopsis, vista dorsal y lateral.

Figure 6. Eragrostis atrovirens (Desf.) Trin. ex Steud., Zizka 1541 (CONC 110022). A. Habit; B. Spikelet; C and D. Caryopsis, dorsal and lateral view. 


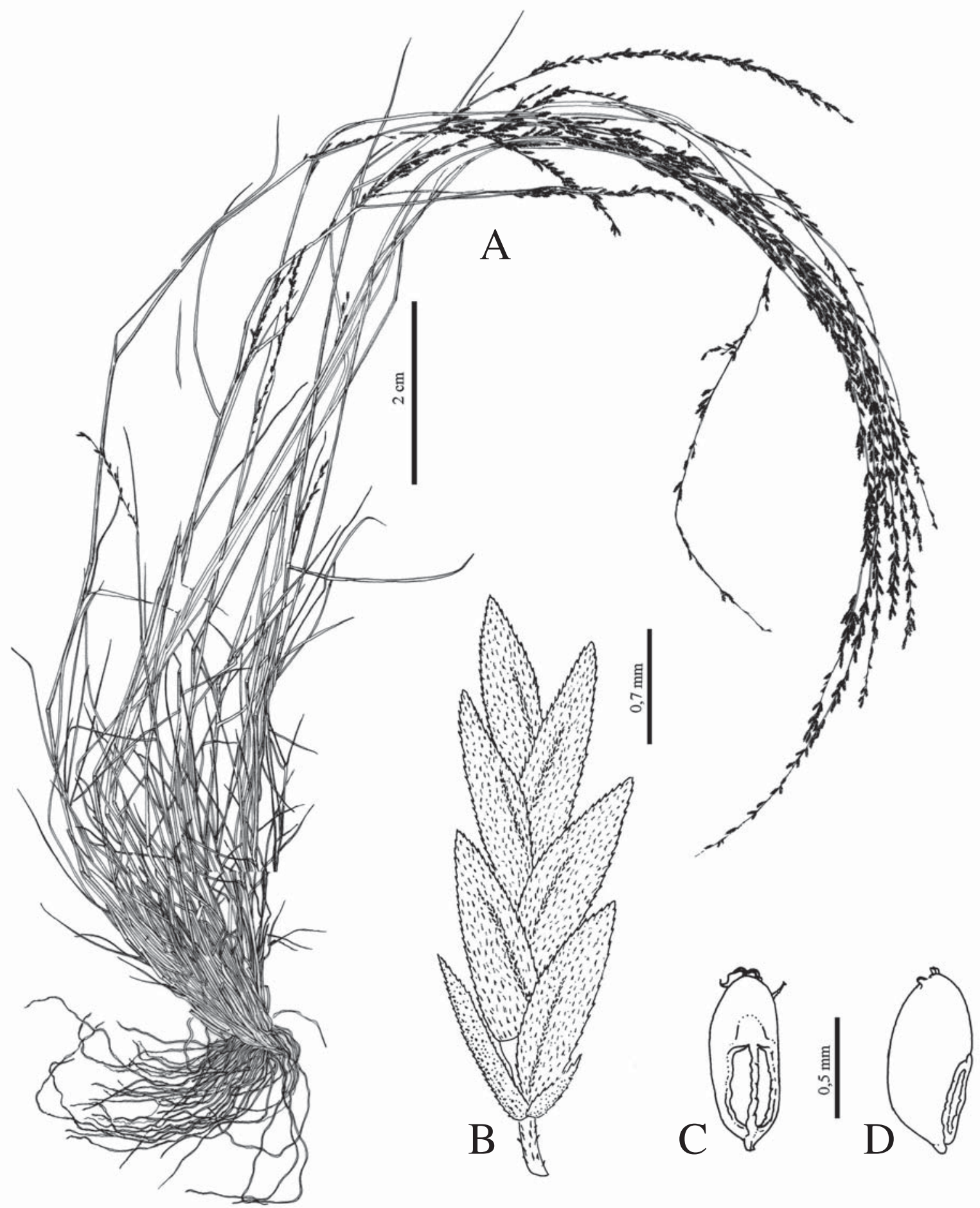

FiguRA 7. Eragrostis attenuata Hitchc., Arancio 10721 (CONC 140340). A. Hábito; B. Espiguilla; C y D. Cariopsis vista dorsal y lateral. FIgURE 7. Eragrostis attenuata Hitchc., Arancio 10721 (CONC 140340). A. Habit; B. Spikelet; C and D. Caryopsis, dorsal and lateral view. 


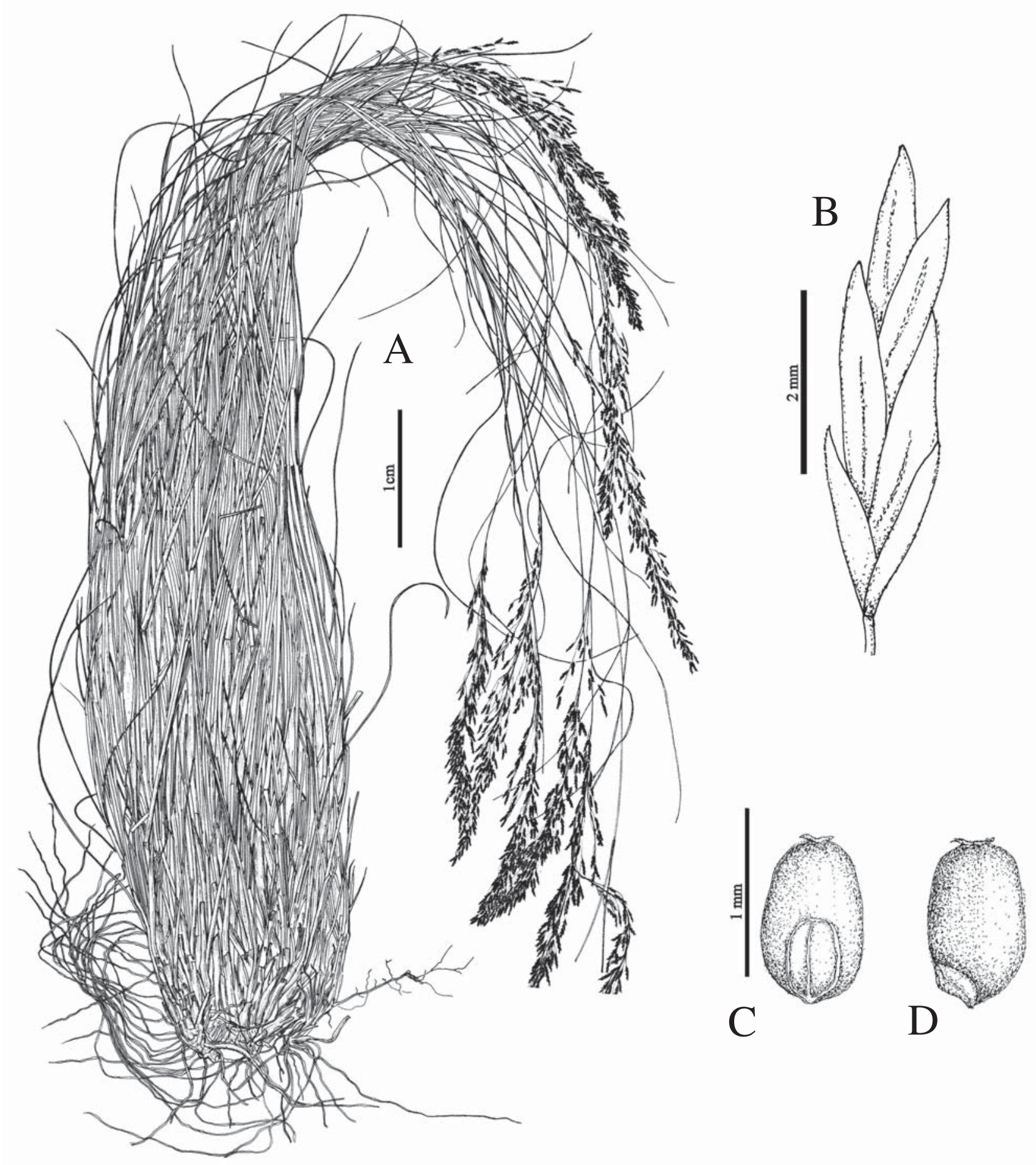

Figura 8. Eragrostis curvula (Schrad.) Nees, Marticorena 1781 (CONC 30276). A. Hábito; B. Espiguilla; C y D. Cariopsis vista dorsal y lateral.

Figure 8. Eragrostis curvula (Schrad.) Nees, Marticorena 1781 (CONC 30276). A. Habit; B. Spikelet; C and D. Caryopsis, dorsal and lateral view. 


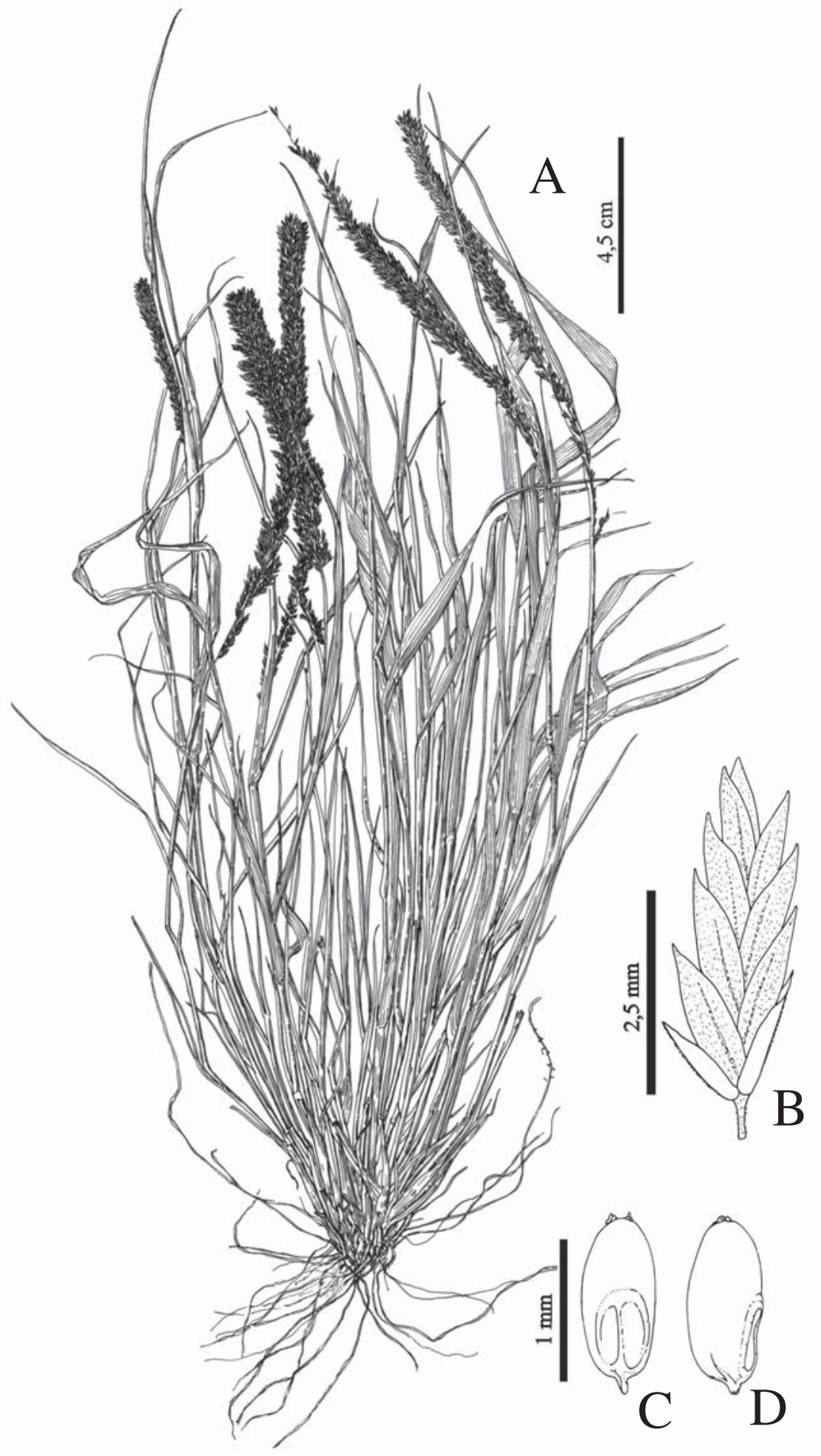

Figura 9. Eragrostis kuschelii Skottsb., Bahamonde s.n. (SGO 122876). A. Hábito; B. Espiguilla; C y D. Cariopsis vista dorsal y lateral. FIgURE 9. Eragrostis kuschelii Skottsb., Bahamonde s.n. (SGO 122876). A. Habit; B. Spikelet; C and D. Caryopsis, dorsal and lateral view. 


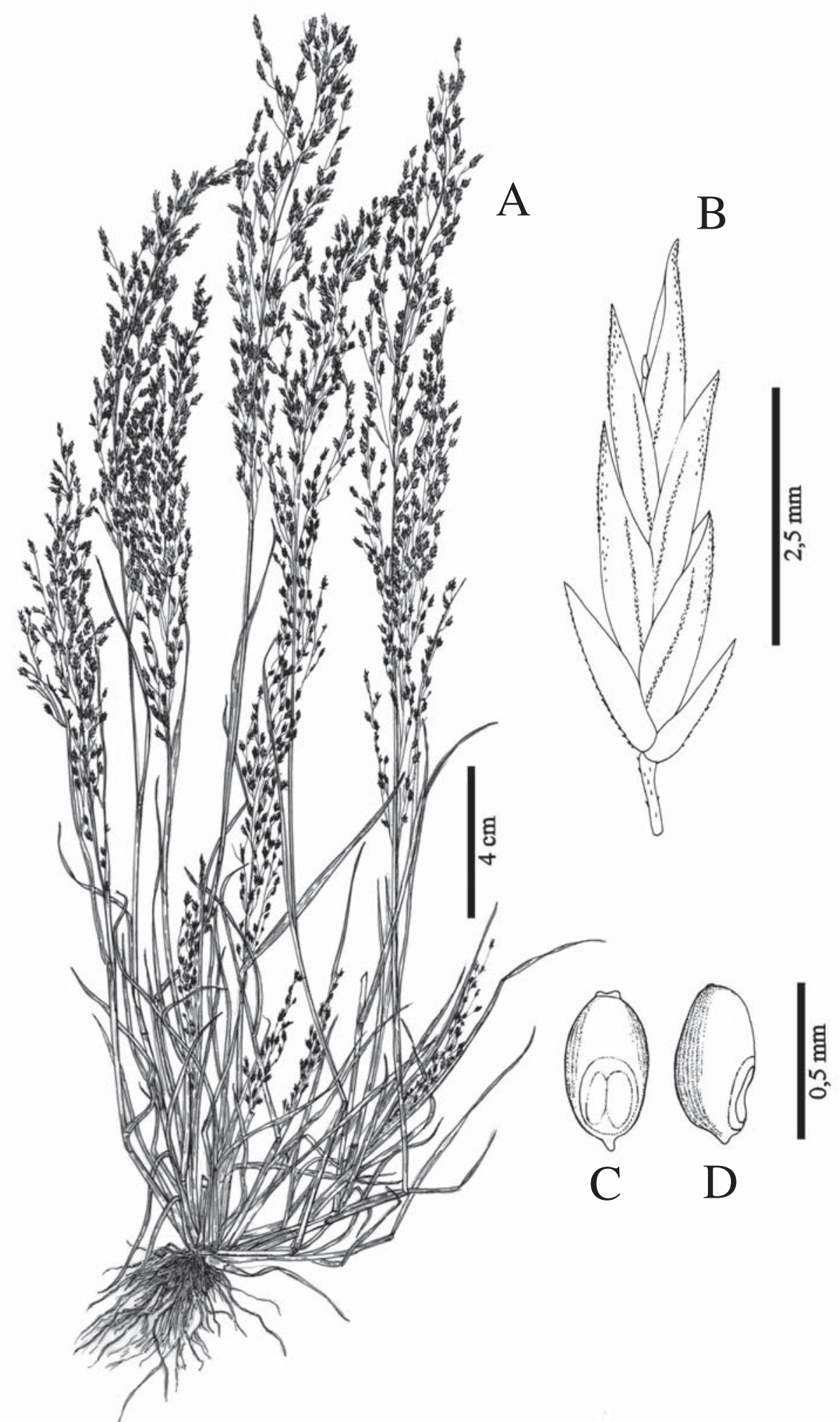

Figura 10. Eragrostis mexicana (Hornem.) Link subsp. virescens (C. Presl) S.D. Koch \& Sánchez Vega, Gunckel 5819 (CONC 10523 ). A. Hábito; B. Espiguilla; C y D. Cariopsis vista dorsal y lateral.

Figure 10. Eragrostis mexicana (Hornem.) Link subsp. virescens (C. Presl) S.D. Koch \& Sánchez Vega, Gunckel 5819 (CONC 10523 ). A. Habit; B. Spikelet; C and D. Caryopsis, dorsal and lateral view. 


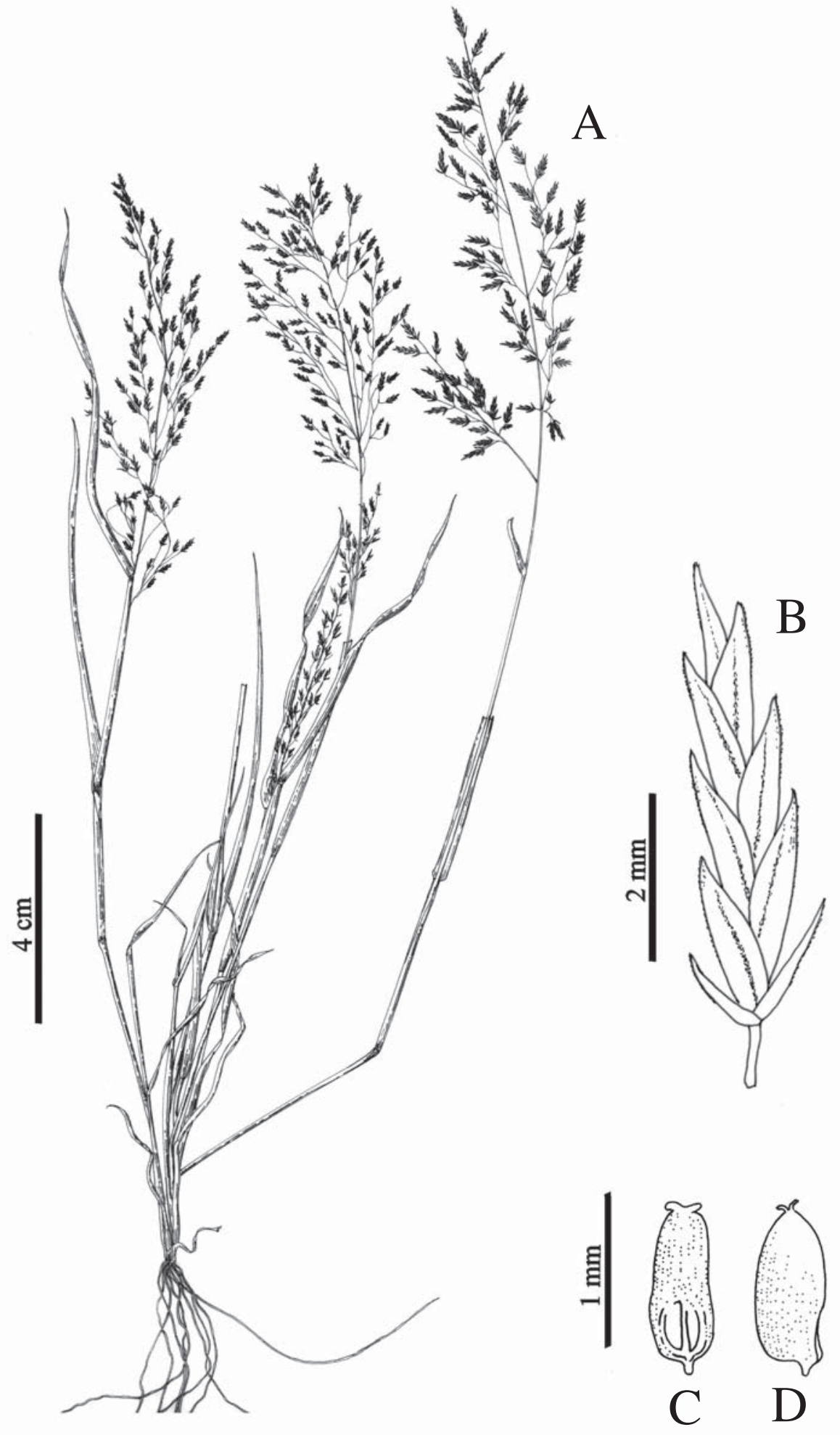

Figura 11. Eragrostis nigricans (Kunth) Steud. var. nigricans, Ackermann 246 (SGO 146175). A. Hábito; B. Espiguilla; C y D. Cariopsis vista dorsal y lateral.

Figure 11. Eragrostis nigricans (Kunth) Steud. var. nigricans, Ackermann 246 (SGO 146175). A. Habit; B. Spikelet; C and D. Caryopsis, dorsal and lateral view. 


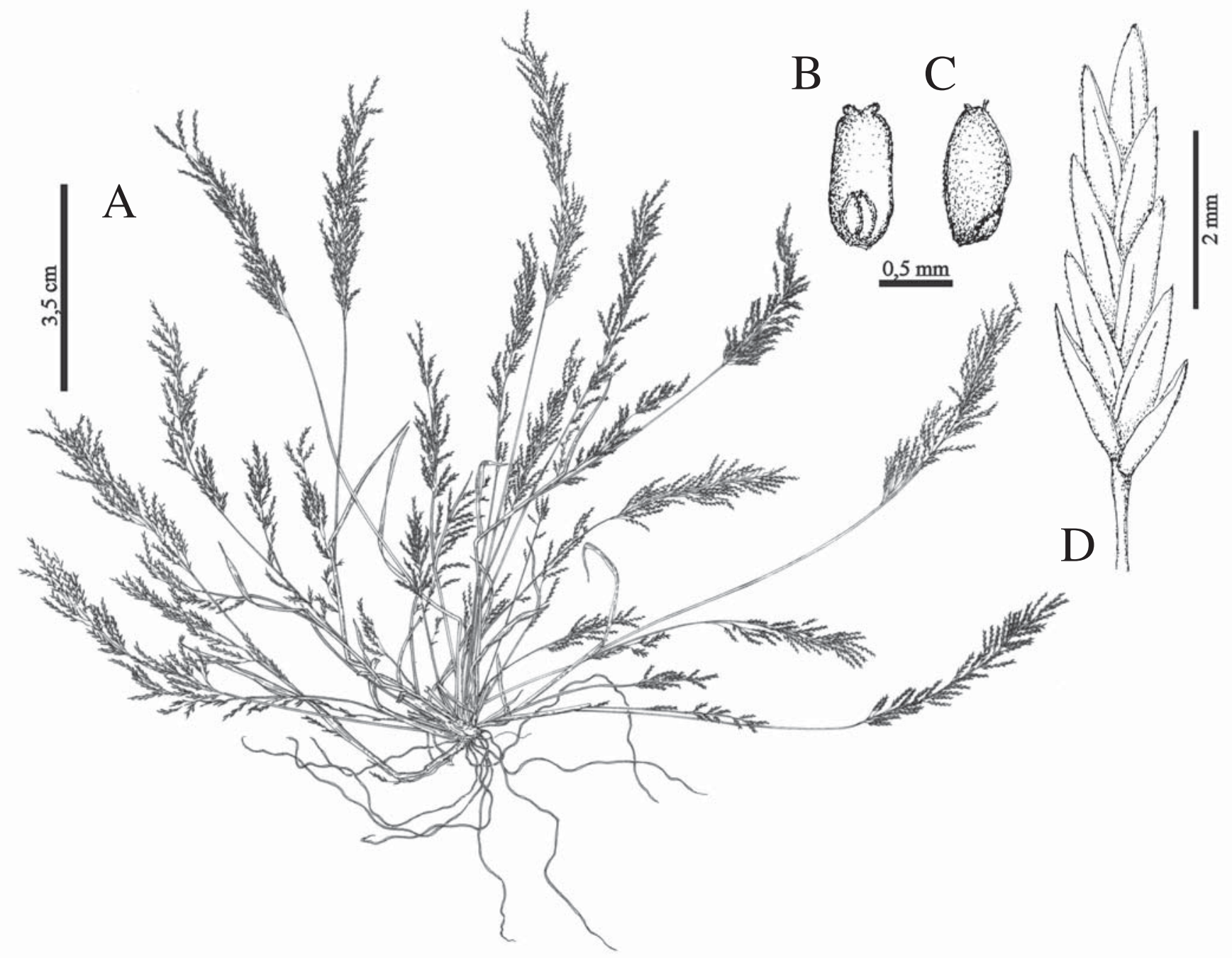

Figura 12. Eragrostis nigricans (Kunth) Steud. var. punensis Nicora, Ricardi Weldt \& Quezada 392 (CONC 54130). A. Hábito; B y C. Cariopsis vista dorsal y lateral; D. Espiguilla.

Figure 12. Eragrostis nigricans (Kunth) Steud. var. punensis Nicora, Ricardi Weldt \& Quezada 392 (CONC 54130). A. Habit; B and C. Caryopsis, dorsal and lateral view; D. Spikelet. 


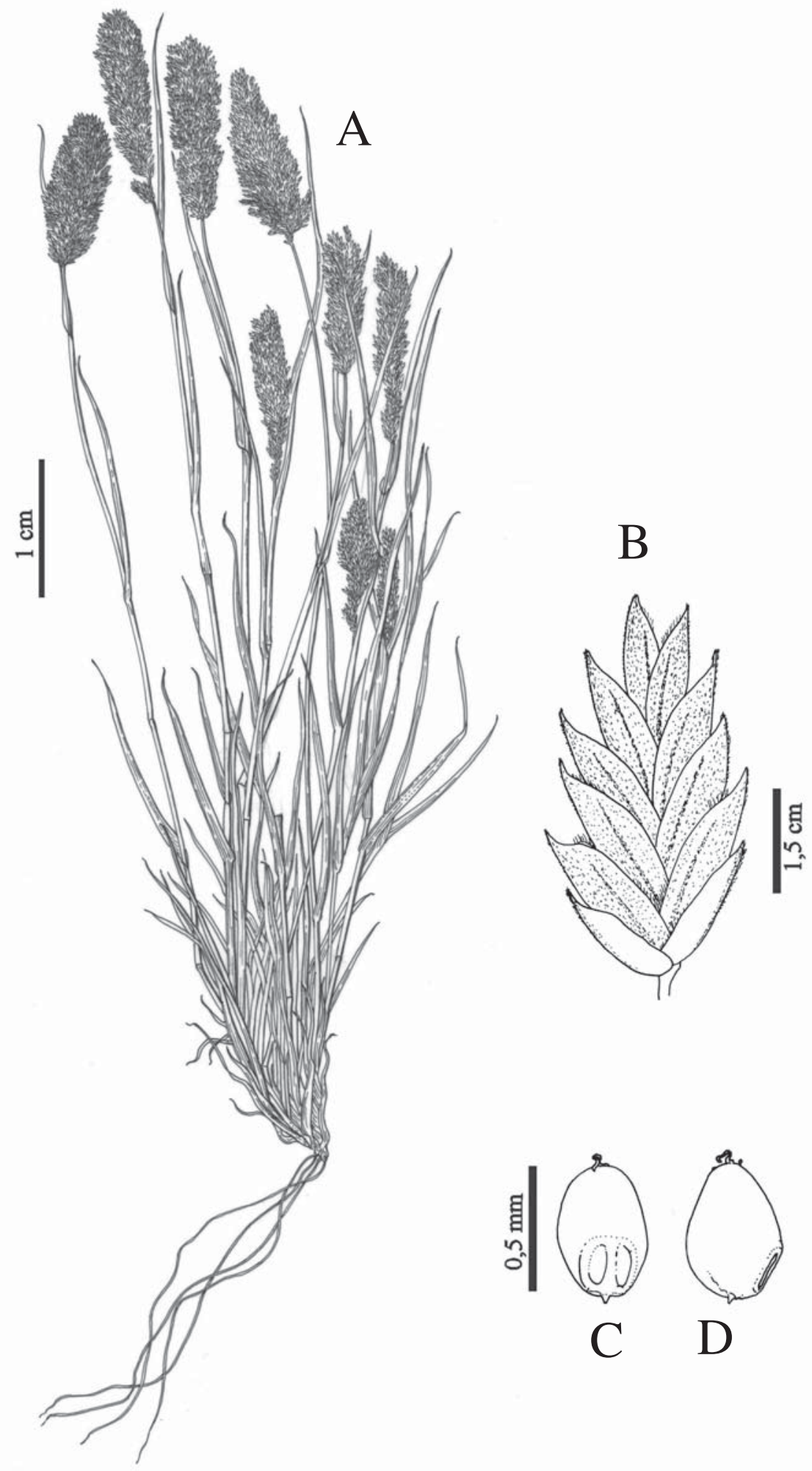

Figura 13. Eragrostis peruviana (Jacq.) Trin., Johow s.n. (SGO 69881). A. Hábito; B. Espiguilla; C y D. Cariopsis vista dorsal y lateral. Figure 13. Eragrostis peruviana (Jacq.) Trin., Johow s.n. (SGO 69881). A. Habit; B. Spikelet; C and D. Caryopsis, dorsal and lateral view. 




Figura 14. Eragrostis pilosa (L.) P. Beauv., CONC 67572. A. Hábito; B. Espiguilla; C y D. Cariopsis vista lateral y dorsal.

FIgURE 14. Eragrostis pilosa (L.) P. Beauv., CONC 67572. A. A. Habit; B. Spikelet; C and D. Caryopsis, lateral and dorsal view. 


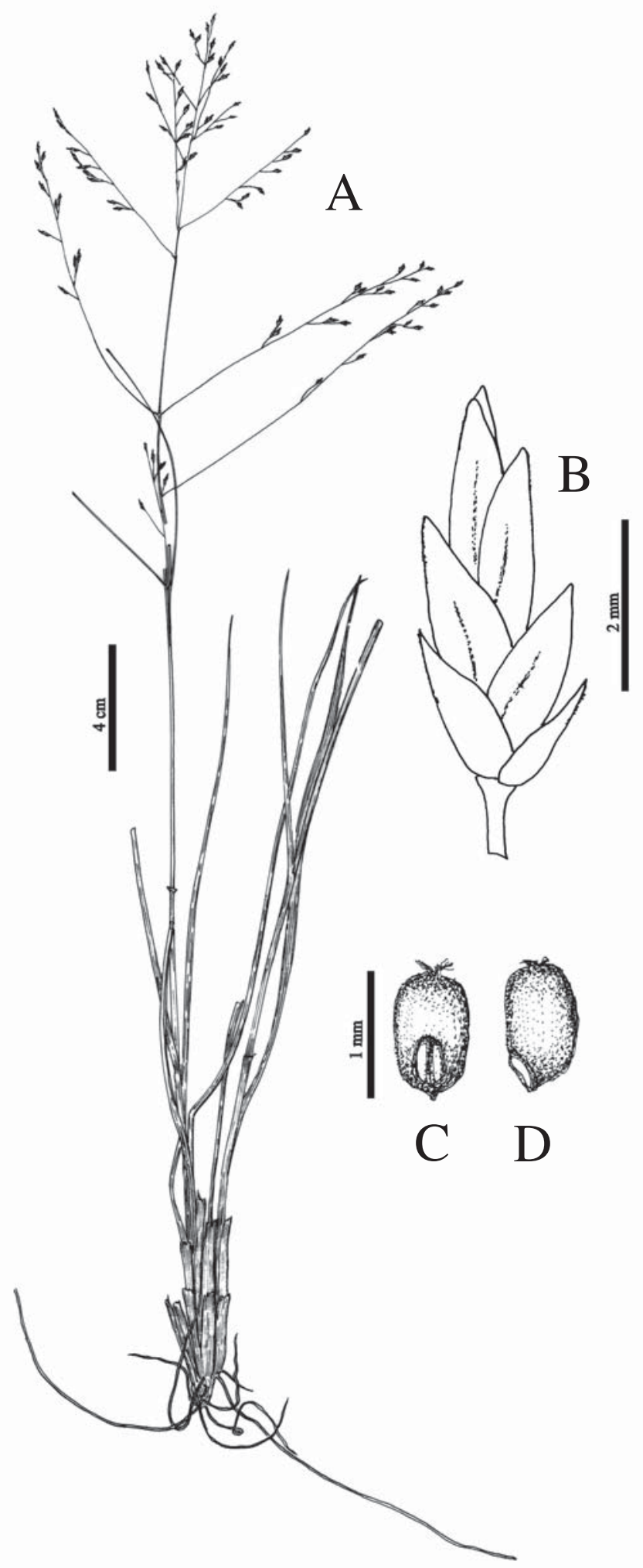

Figura 15. Eragrostis polytricha Nees, Hollermayer 1262 (CONC 68512). A. Hábito; B. Espiguilla; C y D. Cariopsis vista dorsal y lateral.

Figure 15. Eragrostis polytricha Nees, Hollermayer 1262 (CONC 68512). A. Habit; B. Spikelet; C and D. Caryopsis, dorsal and lateral view. 

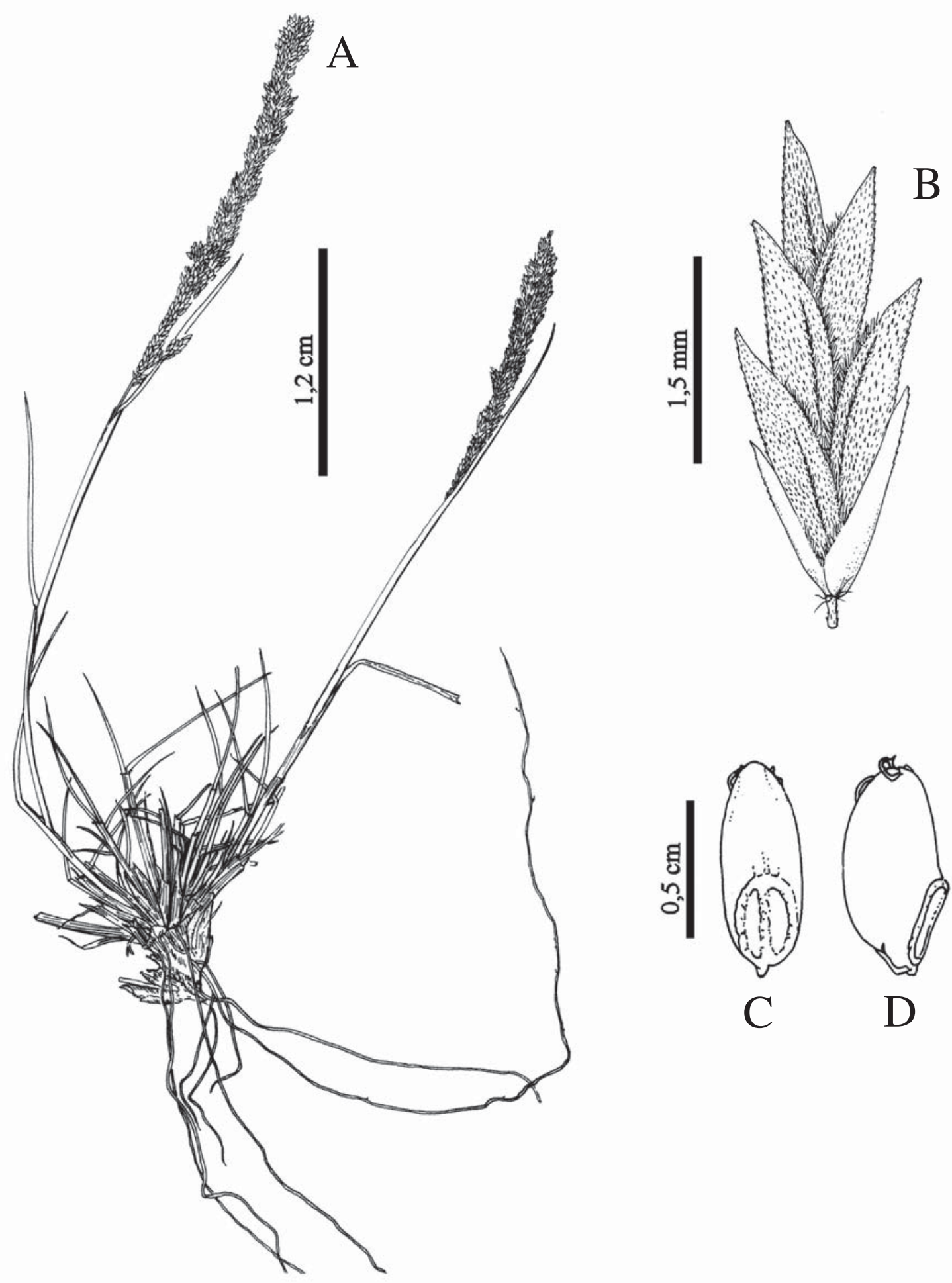

FIGURA 16. Eragrostis pycnantha Phil., Muñoz Pizarro \& Johnson 1982 (SGO 130356). A. Hábito; B. Espiguilla; C y D. Cariopsis vista dorsal y lateral.

Figure 16. Eragrostis pycnantha Phil., Muñoz Pizarro \& Johnson 1982 (SGO 130356). A. Habit; B. Spikelet; C and D. Caryopsis, dorsal and lateral view. 


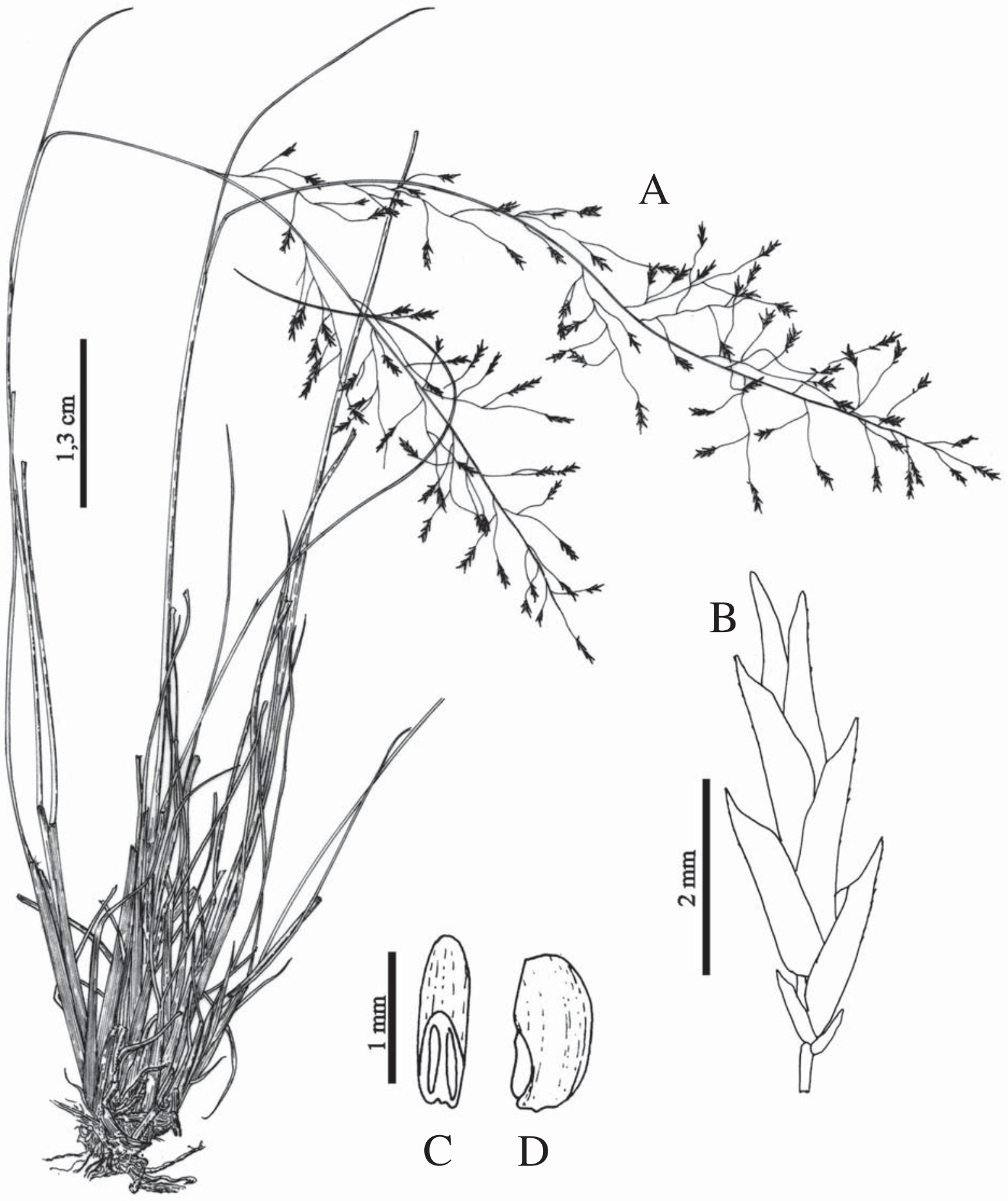

Figura 17. Eragrostis tenuifolia (A. Rich.) Hochst. ex Steud., Lüke 10 (CONC 127864). A. Hábito; B. Espiguilla; C y D. Cariopsis vista dorsal y lateral.

Figure 17. Eragrostis tenuifolia (A. Rich.) Hochst. ex Steud., Lüke 10 (CONC 127864). A. Habit; B. Spikelet; C and D. Caryopsis, dorsal and lateral view. 


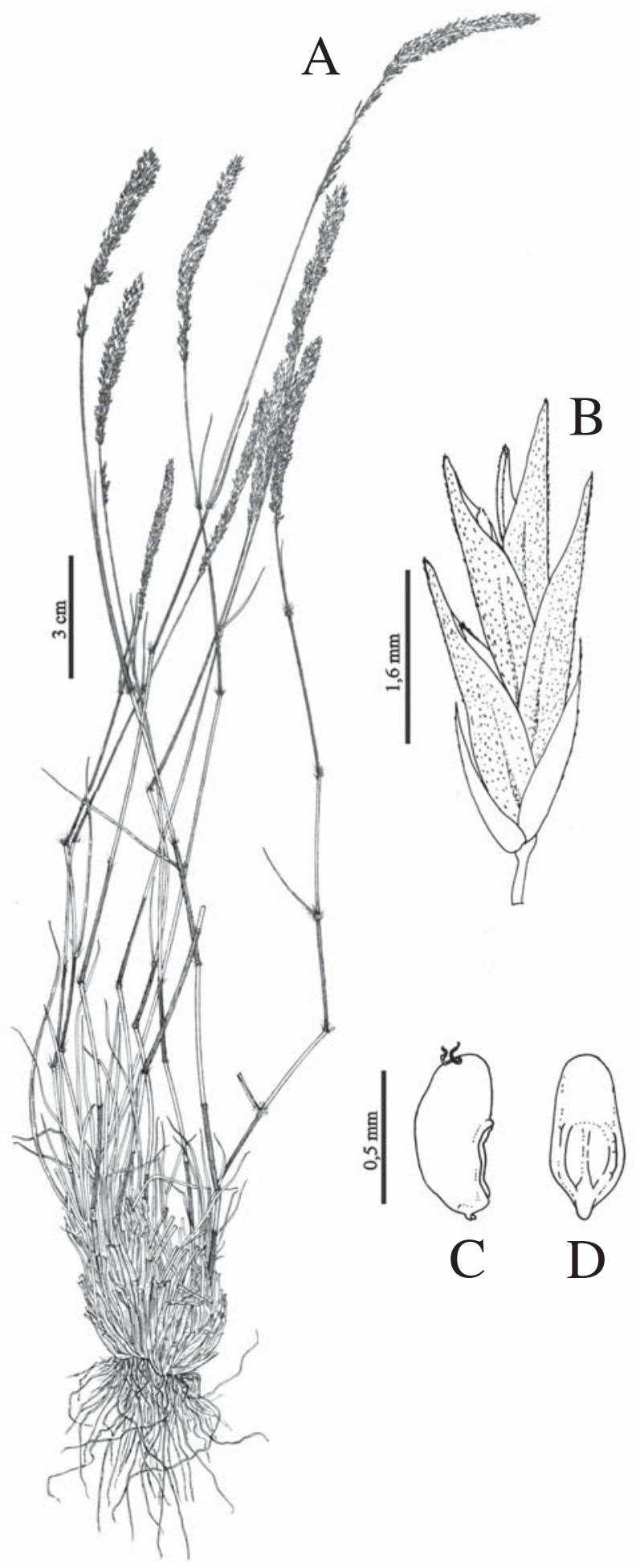

FIgURA 18. Eragrostis weberbaueri Pilg., Belmonte 20194 (CONC 148677). A. Hábito; B. Espiguilla; C y D. Cariopsis vista lateral y dorsal.

Figure 18. Eragrostis weberbaueri Pilg., Belmonte 20194 (CONC 148677). A. Habit; B. Spikelet; C and D. Caryopsis, lateral and dorsal view. 


\section{AGRADECIMIENTOS}

Alos curadores de los herbarios, Mélica Muñoz(SGO), Alicia Marticorena, Clodomiro Marticorena y Roberto Rodríguez (CONC), Ana M. Antón (CORD), Gina Arancio (ULS) y a la Universidad de Concepción (DIUC 204.111.038-1.0). Se agradece a los revisores por sus sugerencias en este trabajo y a Pedro Arias por la elaboración de las ilustraciones.

\section{BIBLIOGRAFÍA}

Boechat, S.C. 1981. Ogénero Eragrostis (Gramineae: Chloridoideae) no Rio Grande do Sul. Porto Alegre. 195 pp.

Boechat, S.C. \& H.M. Longhi-Wagner. 2000. Padrões de distribuição geográfica dos táxons brasileiros de Eragrostis Poaceae (Chloridoideae). Revista Brasileira de Botánica 23(2): 177-194.

Boechat, S.C. \& H.M. LonghI-WAGner. 2001. O gênero Eragrostis no Brasil. Heringia, Série Botánica 55: 23-169.

Cafferty, S., C.E Jarvis \& N.J. Turland. 2000. Typification of Linnaean plant names in the Poaceae (Gramineae). Taxon 49(2): 239-260.

Clayton, W.D. \& S.A. Renvoize. 1986. Genera Graminum, Grasses of the World. Kew Bulletin Additional. Series XIII, $389 \mathrm{pp}$.

CRISCI, J. \& M. LÓPEZ. 1983. Introducción a la teoría y práctica de la taxonomía numérica. Secretaría General de la Organización de los Estados Americanos, Monografía No. 26, Washington, Distrito de Columbia. $132 \mathrm{pp}$.

Cron, G.V., K. Balkwill \& E.B. Knox. 2007. A multivariate analysis of variation in Cineraria lobata L'Hér. and C. ngwenyensis Cron. South African Journal of Botany 73: 530-545.

Cutler, D.F., C.E.J. Botha \& D.W. Stevenson. 2008. Plant Anatomy, an applied approach. Blackwell Publishing. U.K. 302 pp.

Di Rienzo J.A., F. Casanoves, M.G. Balzarini, L. González, M. Tablada, C.W. Robledo. InfoStat versión 2009. Grupo InfoStat, FCA, Universidad Nacional de Córdoba, Argentina.

FAhn, A. \& D.F. Cutler. 1992. Xerophytes. In: H.J. Braun, S. Carlquist, P. Ozenda \& I. Roth (eds.), Handbuch der Pflanzenanatomie. Spezieller Teil, Band XIII, Teil 3. Gebr, Borntraeger, Berlin. 176 pp.

Flores Olvera, H. 2003. Classification of the North American species of Atriplex section Obione (Chenopodiaceae) based on numerical taxonomic analysis. Taxon 52: 247-260.

Giussani, L. M. 2000. Phenetic similarity patterns of dioecious species of Poa from Argentina and neighboring countries. Annales Missouri Botanical Garden 87(2): 203-233.

Giussani, L. M., E. Nicora \& F. Roig. 2000. Poa durifolia y su relación con el patrón fenético de Poa Sect. Dioicopoa (Poaceae). Darwiniana 38(1-2): 47-57.

Gower, J.C. 1971. General coefficient of similarity and some of its properties. Biometrics 27: 857-874.

Henderson, A.J. 2002. Phenetic and phylogenetic analysis of Reinhardtia (Palmae). American Journal of Botany 89 (9): 1491-1502.
Henderson, A.J. 2005. A multivariate study of Calyptrogyne (Palmae). Systematic Botany 30(1): 60-83.

Henderson, A.J. 2006. Traditional morphometrics in plant systematics and its role in palm systematics. Botanical Journal of the Linnean Society 151: 103-111.

Hiтchсоск, A.S. 1927. The grasses of Ecuador, Peru and Bolivia. Contributions from the United States National Herbarium. 24 (8): 335-344.

Hiтchсоск, A.S. 1950. Manual of the grasses of the United States. Second edition. 1051pp.

Holmgren, P.K., N.H. Holmgren \& L.C. Barnett. 1990. Index Herbariorum. Part I: The Herbaria of the World. 693 pp.

Ingram, A.L. \& F.J. Doyle. 2004. Is Eragrostis (Poaceae) monophyletic? Insights from nuclear and plastid sequence data. Systematic Botany 29(3): 545-552.

Laegaard, S. \& P.M. Peterson. 2001. Gramineae (II) Subfam. Chloridoideae. En G. Harling \& L. Andersson (eds.), Flora of Ecuador 68: 1-131.

Legendre, L. \& P. Legendre. 1983. Numerical Ecology. Elsevier, Amsterdam, $419 \mathrm{pp}$.

Marticorena, C. \& M. Quezada. 1985. Catálogo de la Flora Vascular de Chile. Gayana Botánica. 42 (1-2): 1-57.

Matthei, O. 1995. Manual de las malezas que crecen en Chile. Alfabeta impresores. Santiago. Chile. 545 pp.

NicorA, E.G. 1973. Gramíneas nuevas para la flora Argentina. Darwiniana 18(1-2): 265-272.

NicorA, E.G. 1978. Eragrostis Wolf. En: M.N.Correa (ed.), Flora Patagónica 8(3): 480-486.

NicorA, E.G. 1994. Las especies de Eragrostis afines a E. peruviana (Jacq.) Trin. (Gramineae) del norte de Chile y Perú. Gayana Botanica 51: 1-10.

Nicora, E.G. 1998. Revisión del género Eragrostis Wolf (Gramineae-Eragrostideae) para Argentina y países limítrofes. Boissiera 54: 1-109.

Nicora, E.G. \& Z. Rúgulo de Agrasar. 1987. Los Géneros de Gramíneas de América Austral, Argentina, Chile, Uruguay y áreas limítrofes de Bolivia, Paraguay y Brasil. Editorial Hemisferio Sur S.A. 611 pp.

Peñaloza-Jiménez, G., P.M. Peterson \& D. Giraldo-Cañas. 2002. Los géneros Eragrostis y Leptochloa (Poaceae: Cynodonteae) en Colombia. Hickenia 3(35): 133-141.

Peterson, P.M. 2003. Eragrostis Wolf. In Flora de North America North of Mexico. Magnoliophyta: Commelinidae: Poaceae, part 2. volume 25. New York Oxford, Oxford University Press. 65-105.

Peterson, P.M., R.D. Webster \& J. Valdés-Reyna. 1995. Subtribal classification of the new world Eragrostideae (Poaceae: Chloridoideae). Sida 16(3): 529-544.

Peterson, P.M., R.D. Webster \& J. Valdés-Reyna. 1997. Genera of New World Eragrostideae (Poaceae: Chloridoideae). Smithsonian Contributions to Botany 87: 1-50.

Peterson, P.M. \& S.C. Boechat. 2001. Eragrostis Wolf. In: P.M. Peterson, R.J. Soreng, G. Davidse, T.S. Filgueiras, F.O. Zuloaga \& E.J. Judziewicz (eds.), Catalogue of New World Grasses (Poaceae): II. Subfamily Chloridoideae. Contribution United States National Herbarium 41: 81-115.

Peterson, P.M. \& J. Valdés-Reyna . 2005. Eragrostis (Poaceae: Chloridoideae: Eragrostideae: Eragrostidinae) from Northeastern Mexico. Sida 21(3): 1363-1418

PhILLIPS, S.M. 1982. A numerical analysis of Eragrostideae 
(Gramineae). Kew Bulletin 37: 133-162.

Pla, L. 1986. Análisis Multivariado: Método de Componentes Principales. Secretaría General de la Organización de los Estados Americanos, Washington, D.C. 90 pp.

Randall, J.L. \& K.W. Hilu. 1986. Biosystematic Studies of North American Trisetum spicatum (Poaceae). Systematic Botany 11(4): 567-578.

Renvoize, S.A. 1998. Gramíneas de Bolivia. Royal Botanic Gardens, Kew. 644 pp.

RoHLF, F.J. 2005. NTSYSpc, version 2.20L. Exeter Software, Setauket, NY.

Sebola, R. J. \& K. Balkwill. 2009. Numerical phenetic analysis of Olinia rochetiana sensu lato (Oliniaceae). Kew Bulletin 64: 95-121.

SkotTsBerg, C. 1963. Zur Naturgeschichte der Insel San Ambrosio (Islas Desventuradas; Chile). Arkiv för Botanik, n.s. 4(15): 465-488.
Sneath, P.H.A. \& R.R. Sokal. 1973. Numerical Taxonomy. The Principles and Practice of Numerical Classification. Freeman, San Francisco. 573 pp.

Tovar, O. 1993. Las Gramíneas (Poaceae) del Perú. Ruizia 13: $1-480$.

VAN DEN Borre, A. \& L. Watson. 1994. The infrageneric classification of Eragrostis (Poaceae). Taxon 43(3): 383422.

Watson, L. \& M.J. Dallwitz. 1992. The Grass Genera of the World. University Press, Cambridge. 1038 pp.

ZizkA, G. 1991. Flowering plants of eastern island. Palmarum Hortus Francofurtensis. 3:1-84.

Zuloaga, F.O., O. Morrone \& M. Belgrano (Eds). 2008. Catálogo de las Plantas Vasculares del Cono Sur. I. Pteridophyta, Gymnospermae y Monocotyledoneae. Missouri Botanical Garden Press, Saint Louis. 1-983.

ApÉNDICE I. Lista de caracteres y su codificación, usadas en los análisis univariados y multivariados. Caracteres cuantitativos son representados por la moda, unidades de medida y abreviaciones empleadas en el análisis se muestran entre paréntesis.

APPENDIX I. List of characters and coding examined in univariate and multivariate analyses. Quantitative characters are represented by the moda value, units of measure, and abbreviations used in the analysis are shown in parentheses.

1. Ciclo de vida: perennes (0), anuales (1). 2. Hábito: erecto (0), decumbente. (1). 3. Altura de la planta: (cm, longpl). 4. Indumentos de los nudos de la caña: glabros (0), pilosos (1). 5. Indumentos de los entrenudos de la caña: glabros (0), pilosos (1). 6. Glándulas en la zona nodal: ausentes (0), presentes (1). 7. Largo de la vaina: (cm, lgvaina). 8. Relación entre la vaina y los entrenudos: vainas menores que los entrenudos (0), vainas mayores que los entrenudos (1). 9. Indumentos vaina basal: glabras (0), pilosas (1). 10. Indumentos vaina superior: glabras (0), pilosas (1). 11. Tipo de lígula: ciliada (0), pilosa (1), pestañosa (2). 12. Largo de la lígula: ( $\mathrm{mm}$, lglig). 13. Tipo de lámina: planas (0), filiformes (1), convolutas (2). 14. Ancho de la lámina: (mm, alam). 15. Largo de la lámina: (cm, lglam). 16. Indumentos de la lámina: glabras (0), pilosas (1). 17. Tipo de ápice de la lámina: agudas (0), acuminadas (1), obtusas (2). 18. Glándulas sobre las hojas: ausentes (0), presentes (1). 19. Pelos de base tuberculada sobre las hojas: ausentes (0), presentes (1). 20. Glándulas sobre la inflorescencia: ausentes (0), presentes (1). 21. Tipo de panícula: laxa (0), contraída (1). 22. Largo de la panícula: $(\mathrm{cm}$, lginfl). 23. Ancho de la panícula: (cm, ainfl). 24. Pilosidad del eje de la inflorescencia: glabro (0) o piloso (1). 25. Textura del eje de la panícula: glabro (0) o escabroso (1). 26. Pulvínulos: presentes (0), ausentes (1). 27. Forma de la panícula: ovada (0), oblonga (1), elíptica (2). 28. Distribución de las espiguillas en la panícula: concentradas en el ápice de las ramas (0), concentradas homogéneamente hasta la base de las ramas (1). 29. Largo de las ramas basales de la panícula: (cm, lgraminfl). 30 . Largo de la espiguilla: ( $\mathrm{mm}$, lgespig). 31. Ancho de la espiguilla: ( $\mathrm{mm}$, aespig). 32. Forma de la espiguilla: lineares (0), linear-lanceoladas (1), lanceoladas (2), lanceolado-oblongas (3), oblongas (4). 33. Largo del pedicelo de la espiguilla: ( $\mathrm{mm}$, lgpedic). 34. Coloración de la espiguilla: oliváceo (0), violáceo (1). 35. Número de antecios por espiguilla: 3-7-floras (0), 5-10- floras (1), 11-15-floras (2). 36. Raquilla: persistente (0), frágil (1). 37. Articulación de las glumas: caedizas $(0)$, persistentes (1). 38. Largo de la gluma inferior: $(\mathrm{mm}$, lglinf). 39. Largo de la gluma superior: (mm, lglsup). 40. Forma de las glumas: lineares (0), lineares-lanceoladas (1), lanceoladas (2), oval-lanceoladas (3). 41. Consistencia de las glumas: herbáceas (0), membranáceas (1). 42. Tipo de ápice de las glumas: agudas (0), obtusas (1). 43. Indumentos de los márgenes de las glumas: glabros (0), escabrosos (1), ciliolados (2) o escabroso-ciliolado (3). 44. Ancho de la lemma: ( $\mathrm{mm}$, alem). 45. Largo de la lemma: (mm, lglem). 46. Forma de las lemmas: lanceoladas (0), ovallanceladas (1), ovadas (2), oblongas (3). 47. Superficie dorsal de las lemmas: glabra (0), escabrosa (1), escabrosa y ciliada (2). 48. Nervios de la lemma: conspicuos (0), no conspicuos (1). 49. Tipo de ápices de las lemmas: agudas (0), obtusas (1), mucronuladas (2). 50. Largo de la pálea en relación a la lemma: pálea $3 / 4$ de la longitud de la lemma (0), pálea y lemmas de similar longitud (1). 51. Largo de la pálea: ( $\mathrm{mm}$, lpalea). 52. Consistencia de la pálea: herbáceas (0), membranáceas (1). 53. Textura de la nervadura de la pálea: escabrosa (0), escabrosa y ciliada (1), ciliada (2). 54. Superficie de la pálea intercostal: glabra (0) o escabrosa (1). 55. Tipo de ápice de la pálea: agudo (0), obtuso (1). 56. Persistencia de la pálea: caedizas (0), persistentes (1). 57. Largo de la antera: (mm, lanter). 58. Ancho del fruto: ( $\mathrm{mm}$, afruto). 59. Largo del fruto: ( $\mathrm{mm}$, lfruto). 60. Forma del fruto: elipsoide (0), oblongo (1), cuadrilongo (2), ovado (3). 61. Largo de la mácula embrional: igual a la mitad de la longitud del fruto (0), menor a la mitad de la longitud del fruto (1), 1/3 de la longitud del fruto (2). 62. Surco ventral del fruto: presente (0), ausente (1). 63. Margen del ápice de las glumas: entero (0) o denticulado (1). 


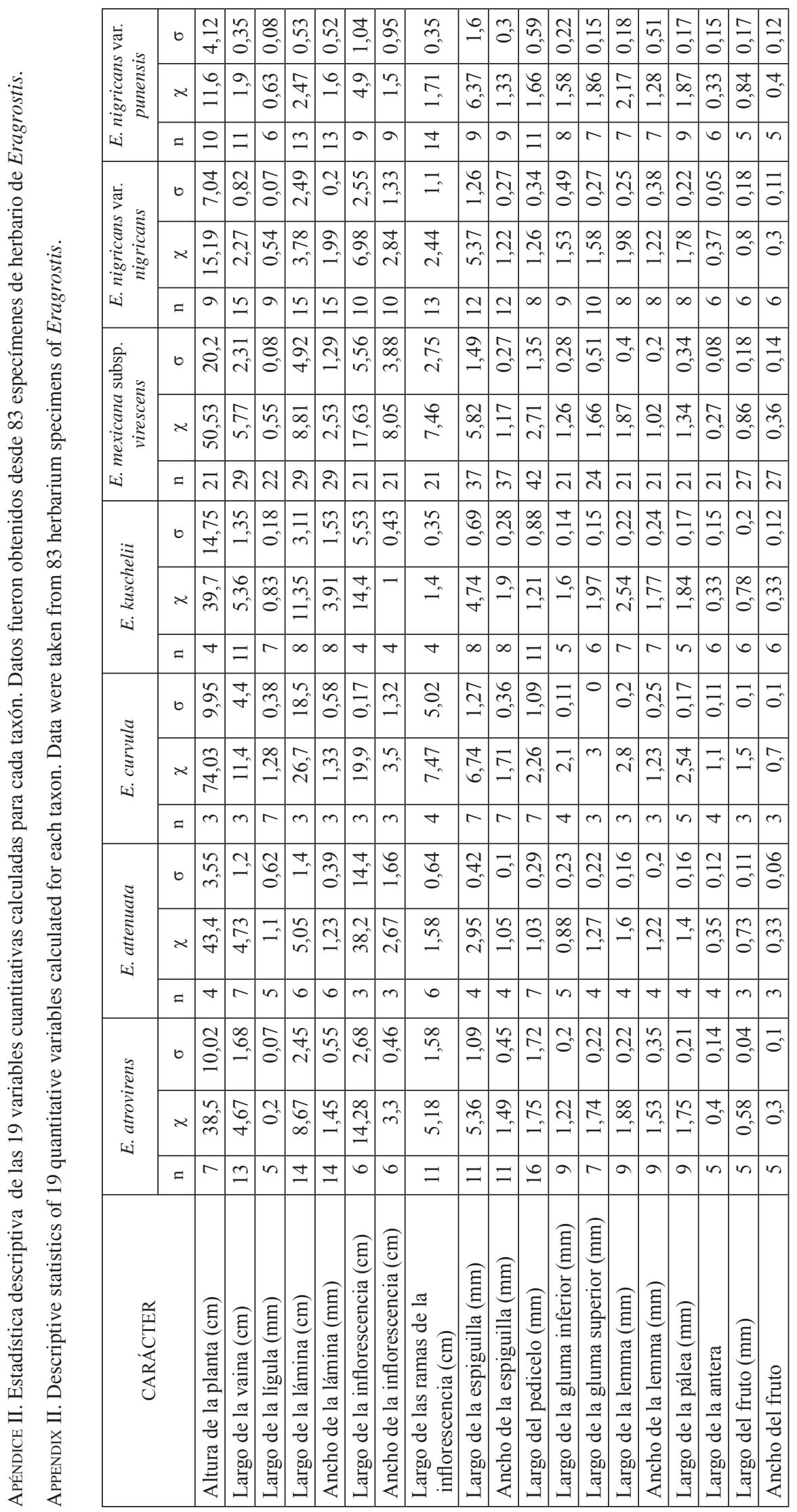




\begin{tabular}{|c|c|c|c|c|c|c|c|c|c|c|c|c|c|c|c|c|c|c|c|c|}
\hline \multirow{3}{*}{ 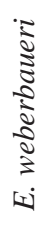 } & 0 & $\hat{\infty}^{\circ}$ & $\stackrel{0}{=}$ & ָे & $\tilde{N}$ & $\underset{\sim}{\stackrel{f}{f}}$ & $\bar{\sigma}$ & సે & $\begin{array}{l}I_{0} \\
0\end{array}$ & $\stackrel{n}{n}$ & 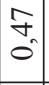 & $\begin{array}{l}0 \\
0 \\
0\end{array}$ & $\begin{array}{l}+ \\
m \\
0^{2}\end{array}$ & $\frac{0}{0}$ & $\begin{array}{l}m \\
\tilde{\sigma} \\
\hat{n}\end{array}$ & $\begin{array}{l}n \\
0\end{array}$ & $\begin{array}{c}\infty \\
\overrightarrow{0}\end{array}$ & $\begin{array}{l}0 \\
0 \\
0\end{array}$ & $\bar{z}$ & $\begin{array}{l}\text { oे } \\
\text { o }\end{array}$ \\
\hline & $\nsim$ & 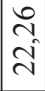 & co & $\begin{array}{l}\Delta \\
\sigma \\
\sigma\end{array}$ & $\begin{array}{l}8 \\
8 \\
+\end{array}$ & $\Xi$ & $\hat{0}$ & $\begin{array}{l}\infty \\
0 \\
0\end{array}$ & $\underset{\sim}{\approx}$ & $\begin{array}{l}n \\
n \\
n\end{array}$ & $\overbrace{0}$ & $\bar{\sigma}$ & $\vec{\nabla}_{0}$ & $\stackrel{\infty}{\infty}$ & $\begin{array}{l}0 \\
\text { v } \\
\text { i }\end{array}$ & $\stackrel{\sim}{\sim}$ & $\begin{array}{l}\tilde{m} \\
\rightarrow \\
-\end{array}$ & \begin{tabular}{l}
$\infty$ \\
\multirow{0}{0}{} \\
0
\end{tabular} & $\frac{\infty}{\sigma}$ & $\begin{array}{l}\text { ते } \\
0\end{array}$ \\
\hline & $\Rightarrow$ & \pm & $\stackrel{2}{2}$ & $\simeq$ & 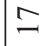 & 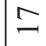 & $\because$ & $\because$ & $\simeq$ & $\cong$ & $\cong$ & $\simeq$ & $=$ & 으. & $=$ & $=$ & $=$ & 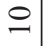 & 이 & 으 \\
\hline \multirow{3}{*}{ 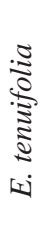 } & 0 & $\begin{array}{l}\circ \\
2 \\
0\end{array}$ & $\begin{array}{l}0 \\
n \\
0\end{array}$ & 10 & 0 & 0 & $\stackrel{\sim}{-}$ & 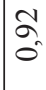 & $\frac{ \pm}{0}$ & $\cong$ & $\frac{ \pm}{0}$ & $\approx$ & $\frac{ \pm}{0}$ & 0 & $\frac{ \pm}{0^{\circ}}$ & 0 & $\frac{ \pm}{0^{\circ}}$ & 0 & 0 & 0 \\
\hline & 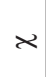 & $\vec{m}$ & 으 & ô & $\begin{array}{l}0 \\
10\end{array}$ & - & 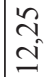 & $\stackrel{n}{m}$ & $\begin{array}{l}0 \\
\text { ले }\end{array}$ & in & $\because$ & $\frac{n}{n}$ & $\hat{\sigma}^{\circ}$ & $\stackrel{\sim}{\sim}$ & 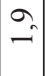 & - & $\because$ & $\stackrel{\dot{\sigma}_{0}}{ }$ & -1 & $\begin{array}{l}0 \\
0^{\circ}\end{array}$ \\
\hline & $=$ & $\sim$ & $N$ & - & - & - & $N$ & $N$ & $N$ & $\sim$ & $N$ & $\sim$ & $\sim$ & - & $N$ & $N$ & $N$ & - & - & - \\
\hline \multirow{3}{*}{ 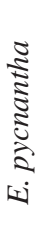 } & 0 & $\stackrel{n}{\stackrel{n}{f}}$ & $\stackrel{0}{=}$ & 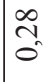 & $\overline{0}$ & $\begin{array}{l}0 \\
2 \\
0 \\
0\end{array}$ & $\stackrel{\infty}{=}$ & ○ & $\begin{array}{l}\text { to } \\
\text { to }\end{array}$ & ñ & 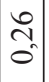 & $\begin{array}{l}2 \\
\tilde{m} \\
0\end{array}$ & $\frac{m}{0}$ & 0 & $\frac{ \pm}{0}$ & $\begin{array}{l}\infty \\
\text { ஸे } \\
0\end{array}$ & $\vec{z}$ & $\overrightarrow{0}$ & $\overrightarrow{0^{\prime}}$ & $\begin{array}{l}0 \\
0 \\
0\end{array}$ \\
\hline & $\times$ & $\frac{n}{\infty}$ & \% & $\infty$ & $\begin{array}{l}n \\
\text { in }\end{array}$ & $\hat{\sigma}$ & $\sigma_{0}^{\circ}$ & 市 & $\stackrel{\sim}{\leftrightarrows}$ & $\stackrel{\sim}{f}$ & $\mid \begin{array}{l}\infty \\
\infty \\
-\end{array}$ & $\begin{array}{l}\infty \\
\sigma \\
\sigma\end{array}$ & 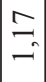 & $N$ & $\vec{i}$ & $\infty$ & $\hat{\infty}$ & $\hat{o}$ & $\frac{m}{0}$ & $\hat{n}$ \\
\hline & $\Rightarrow$ & $\nabla$ & in & N & 6 & 6 & $m$ & $m$ & $\nabla$ & in & $n$ & $\nabla$ & $\nabla$ & $\sim$ & $N$ & $\sim$ & $n$ & $n$ & $n$ & $m$ \\
\hline \multirow{3}{*}{ 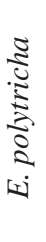 } & 0 & $\hat{n}$ & $\vec{n}$ & $\frac{ \pm}{0}$ & $\stackrel{N}{\tilde{r}}$ & $\frac{n}{0}$ & $\begin{array}{l}\infty \\
i \\
n\end{array}$ & $\vec{m}$ & $\begin{array}{l}\vec{\forall} \\
\text { i }\end{array}$ & $\frac{+}{\sigma_{0}}$ & 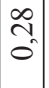 & $\frac{m}{i}$ & $\begin{array}{l}2 \\
0\end{array}$ & $\begin{array}{l}m \\
0\end{array}$ & $\frac{n}{0}$ & $\frac{5}{0}$ & $\begin{array}{c}0 \\
-1 \\
0\end{array}$ & $\begin{array}{l}0 \\
\delta_{0}\end{array}$ & $\frac{m}{0}$ & $\frac{1}{0}$ \\
\hline & 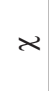 & $\begin{array}{l}n \\
n \\
0 \\
n \\
n\end{array}$ & ț & 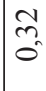 & 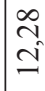 & $\frac{\infty}{m}$ & 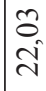 & $\begin{array}{l}\mathscr{f} \\
\stackrel{2}{2}\end{array}$ & $\begin{array}{l}2 \\
\stackrel{2}{=}\end{array}$ & $\overrightarrow{\tilde{m}^{\prime}}$ & $\stackrel{\hat{\sim}}{-}$ & $\mid \begin{array}{l}\infty \\
0 \\
+\end{array}$ & $\stackrel{\Xi}{\sim}$ & $\approx$ & 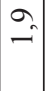 & 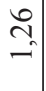 & $\begin{array}{l}\infty \\
\approx \\
\sim\end{array}$ & $\begin{array}{l}\mathscr{r} \\
\mathfrak{f}^{\prime}\end{array}$ & $\hat{0}$ & $\begin{array}{l}\vec{\forall} \\
\sigma_{0}\end{array}$ \\
\hline & $=$ & $\because$ & \pm & $\because$ & \pm & \pm & $\because$ & $\because$ & t & $\approx$ & ה & m & 0 & 0 & $\Xi$ & \pm & \pm & \pm & \pm & \pm \\
\hline \multirow{3}{*}{ 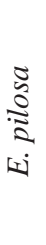 } & 0 & ते & $\bar{F}$ & $\overrightarrow{0}$ & $\frac{n}{r}$ & $\widetilde{\sigma}$ & $\begin{array}{l}\hat{2} \\
\hat{0}\end{array}$ & $\frac{m}{2}$ & $\begin{array}{l}\stackrel{\vartheta}{f} \\
\dot{f}\end{array}$ & $\Xi$ & 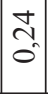 & $\begin{array}{l}\vec{\gamma} \\
i\end{array}$ & $\begin{array}{l}\vec{\sigma}_{0} \\
\sigma_{0}\end{array}$ & $\stackrel{\mathscr{r}}{\sigma}_{\sigma}$ & 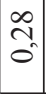 & $\mid \begin{array}{c}0 \\
\cdots \\
0\end{array}$ & $\begin{array}{c}\stackrel{1}{1} \\
0 \\
0\end{array}$ & $\begin{array}{l}\mathscr{c} \\
0 \\
0\end{array}$ & $\frac{\triangle}{0}$ & $\begin{array}{l}\infty \\
0 \\
0\end{array}$ \\
\hline & $x$ & $\begin{array}{l}\tilde{n} \\
m \\
m\end{array}$ & $\begin{array}{l}\bar{\sigma} \\
\dot{\gamma}\end{array}$ & $\underset{\leftarrow}{\tilde{\sigma}}$ & $\infty$ & $\stackrel{\tilde{\sigma}}{\sim}$ & $\begin{array}{l}\infty \\
\infty \\
n \\
-1\end{array}$ & $\stackrel{\gamma}{\gamma}$ & 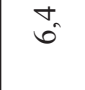 & $\begin{array}{l}\hat{\sigma} \\
+\end{array}$ & $\Rightarrow$ & $\begin{array}{l}\stackrel{+}{n} \\
\text { m. }\end{array}$ & $\frac{\infty}{\sigma^{0}}$ & $\stackrel{n}{n}$ & $\stackrel{\infty}{-}$ & - & $\underset{\sim}{\sim}$ & $\begin{array}{c}\tilde{N} \\
\tilde{0}\end{array}$ & $\begin{array}{l}2 \\
0 \\
0\end{array}$ & 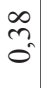 \\
\hline & $=$ & in & $\infty$ & 6 & 6 & 0 & in & in & in & $\infty$ & $\infty$ & 으 & 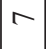 & 0 & $\nabla$ & $\nabla$ & $n$ & $\nabla$ & $n$ & $n$ \\
\hline \multirow{3}{*}{ 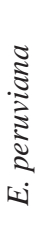 } & 0 & $\begin{array}{l}\infty \\
2 \\
\text { n. }\end{array}$ & $\frac{0}{N}$ & $\hat{\sim}$ & $\begin{array}{l}\infty \\
0 \\
0\end{array}$ & $\Xi$ & $\begin{array}{l}n \\
n \\
n\end{array}$ & $\frac{9}{0}$ & $\stackrel{0}{\dddot{0}}$ & $\stackrel{\infty}{\stackrel{0}{-}}$ & $\begin{array}{l}0 \\
0\end{array}$ & $\overrightarrow{\tilde{n}}$ & $=$ & $\overrightarrow{\widetilde{N}}$ & $\frac{1}{0}$ & స̃. & $\frac{a}{0}$ & $\begin{array}{l}\Xi_{0} \\
0^{\circ}\end{array}$ & $\frac{1}{0}$ & $\begin{array}{l}2 \\
0 \\
0\end{array}$ \\
\hline & $x$ & $\begin{array}{l}\bar{m} \\
\hat{\sigma}\end{array}$ & $\begin{array}{l}\tilde{\infty} \\
\hat{N}\end{array}$ & $\frac{\infty}{0}$ & $\begin{array}{l}\infty \\
\text { s } \\
\text { n. }\end{array}$ & $\begin{array}{l}\mathcal{6} \\
\text { i }\end{array}$ & $\begin{array}{l}\infty \\
\sigma \\
\gamma\end{array}$ & $\stackrel{\infty}{\infty}$ & $\frac{n}{a}$ & $\begin{array}{l}\overrightarrow{\sigma_{m}} \\
\tilde{n}^{2}\end{array}$ & $\begin{array}{l}2 \\
\text { ja } \\
\text { an }\end{array}$ & $\begin{array}{l}\tilde{n} \\
\tilde{0}\end{array}$ & $\stackrel{\infty}{\sim}$ & $\stackrel{\infty}{=}$ & $\overrightarrow{\mathrm{d}}$ & $\begin{array}{l}\hat{\mathrm{m}} \\
-\end{array}$ & $\stackrel{\nabla}{f}_{0}$ & $\stackrel{I}{0}$ & $\begin{array}{l}\hat{6} \\
0\end{array}$ & $\hat{o}^{n}$ \\
\hline & $=$ & $\because$ & $\stackrel{\infty}{-}$ & 으 & I & I & $\cong$ & 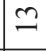 & $a$ & $\cong$ & $\simeq$ & $=$ & $a$ & $a$ & 0 & 이 & 이 & $\infty$ & 이 & 으 \\
\hline \multicolumn{2}{|c|}{ 总 } & 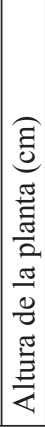 & 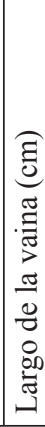 & 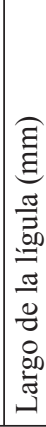 & 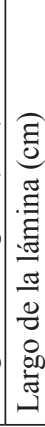 & 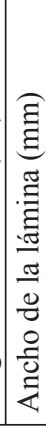 & 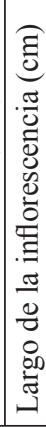 & 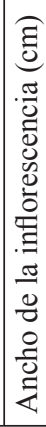 & 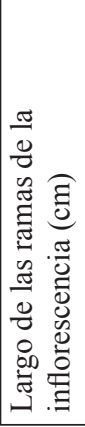 & 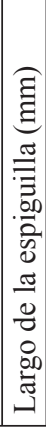 & 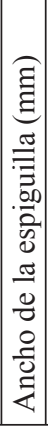 & 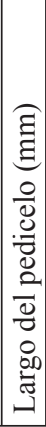 & 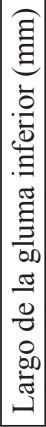 & 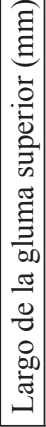 & 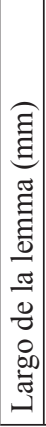 & 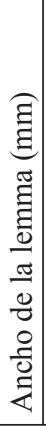 & 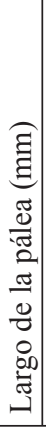 & 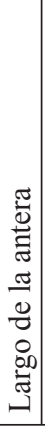 & 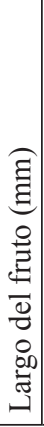 & 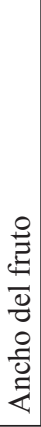 \\
\hline
\end{tabular}

